\title{
RAGE is a nucleic acid receptor that promotes inflammatory responses to DNA
}

\author{
Cherilyn M. Sirois, ${ }^{1,6}$ Tengchuan Jin, ${ }^{2}$ Allison L. Miller, ${ }^{3}$ \\ Damien Bertheloot, ${ }^{5}$ Hirotaka Nakamura, ${ }^{1}$ Gabor L. Horvath, ${ }^{1,5}$ \\ Abubakar Mian, ${ }^{2}$ Jiansheng Jiang, ${ }^{2}$ Jacob Schrum,,${ }^{1}$ Lukas Bossaller, ${ }^{1}$ \\ Karin Pelka, ${ }^{5}$ Natalio Garbi, ${ }^{7}$ Yambasu Brewah, ${ }^{3}$ Jane Tian, ${ }^{3}$ \\ ChewShun Chang, ${ }^{4}$ Partha S. Chowdhury, ${ }^{4}$ Gary P. Sims, ${ }^{3}$ Roland Kolbeck, ${ }^{3}$ \\ Anthony J. Coyle, ${ }^{3,6}$ Alison A. Humbles, ${ }^{3}$ T. Sam Xiao, ${ }^{2}$ and Eicke Latz ${ }^{1,5,7}$ \\ 'Department of Medicine, Division of Infectious Diseases and Immunology, University of Massachusetts Medical School, \\ Worcester, MA 01605 \\ ${ }^{2}$ Structural Immunobiology Unit, Laboratory of Immunology, National Institute of Allergy and Infectious Diseases, National \\ Institutes of Health, Bethesda, MD 20892 \\ ${ }^{3}$ Division of Respiratory, Inflammation and Autoimmunity and ${ }^{4}$ Department of Antibody Discovery and Protein Engineering, \\ Medlmmune LLC, Gaithersburg, MD 20878 \\ 5 Institute of Innate Immunity, University of Bonn, 53127 Bonn, Germany \\ ${ }^{6}$ Centers for Therapeutic Innovation, Pfizer Inc., Boston, MA 02115 \\ ${ }^{7}$ German Center for Neurodegenerative Diseases (DZNE), 53175 Bonn, Germany
}

\begin{abstract}
Recognition of DNA and RNA molecules derived from pathogens or self-antigen is one way the mammalian immune system senses infection and tissue damage. Activation of immune signaling receptors by nucleic acids is controlled by limiting the access of DNA and RNA to intracellular receptors, but the mechanisms by which endosome-resident receptors encounter nucleic acids from the extracellular space are largely undefined. In this study, we show that the receptor for advanced glycation end-products (RAGE) promoted DNA uptake into endosomes and lowered the immune recognition threshold for the activation of Toll-like receptor 9, the principal DNA-recognizing transmembrane signaling receptor. Structural analysis of RAGE-DNA complexes indicated that DNA interacted with dimers of the outermost RAGE extracellular domains, and could induce formation of higher-order receptor complexes. Furthermore, mice deficient in RAGE were unable to mount a typical inflammatory response to DNA in the lung, indicating that RAGE is important for the detection of nucleic acids in vivo.
\end{abstract}

\section{CORRESPONDENCE}

Eicke Latz:

eicke.latz@uni-bonn.de

T. Sam Xiao:

xiaot@niaid.nih.gov

Abbreviations used: BAL, bronchoalveolar lavage; ds, double stranded; FRET, Förster resonance energy transfer; HEK, human embryonic kidney; LIX, LPS-induced CXC chemokine; MPO, myeloperoxidase; ODN, oligodeoxynucleotides; PEI, polyethyleneimine; RAGE, receptor for advanced glycation end-products; ss, single stranded.
Infection and tissue damage cause an immediate inflammatory response that is characterized by the activation of innate immune cells and other local stromal cells, followed by rapid recruitment of additional immune cells to the affected site. This response serves to control the invading pathogen and to initiate reparative processes that restore tissue function. Certain surface-exposed immune receptors recognize several lipidated or proteinaceous activators that are foreign to the host, such as lipopeptides (TLR2), LPSs (TLR4), and flagellin (TLR5). In contrast, all nucleic acid-sensing immune receptors described to date are expressed in endolysosomal compartments

C.M. Sirois and T. Jin contributed equally to this paper. C.M. Sirois's present address is Center for Translational Research, University of the Americas, Quito, Ecuador.
(TLR3, TLR7-9; Takeda et al., 2003) or in the cytosol (RIG-I family members, AIM2, IFI16, and others; Hornung and Latz, 2010; Ranjan et al., 2009), and thus are sequestered away from the extracellular milieu. This internal location of nucleic acid sensing receptors has been proposed to limit receptor triggering by self-nucleic acids that are present in the extracellular space under homeostatic conditions. Indeed, experimental mislocalization of TLR9, a nonredundant endosomal signaling receptor for DNA, to the plasma membrane led to the recognition of

(0) 2013 Sirois et at. This article is distributed under the terms of an AttributionNoncommercial-Share Alike-No Mirror Sites license for the first six months after the publication date (see http://www.rupress.org/terms). After six months it is available under a Creative Commons License (Attribution-NoncommercialShare Alike 3.0 Unported license, as described at http://creativecommons.org/ icenses/by-nc-sa/3.0/). 
self-DNA from the extracellular environment (Barton et al., 2006). At the same time, endosomal localization of TLR 9 is required for efficient recognition of viral DNA, suggesting that nucleic acids become concentrated in endosomal compartments or that additional mechanisms of receptor processing are required for nucleic acid recognition in the endosome (Ewald et al., 2008, 2011; Park et al., 2008).

Along with compartmentalization, other safeguards typically prevent self-nucleic acid recognition by innate immune receptors. For instance, digestion of DNA by extracellular and intracellular nucleases ensures that self-DNA released under normal conditions escapes detection by nucleic acid sensors (Napirei et al., 2000; Evans and Aguilera, 2003; Kawane et al., 2010). However, if nucleic acid concentrations exceed the nuclease capacity, such as during infections or in situations of increased cell damage, signaling receptors and their downstream inflammatory effects can be triggered. Chronic activation of inflammatory responses by nucleic acids can result in undesirable autoimmune syndromes and dramatic pathologies (Crow and Rehwinkel, 2009; Horton et al., 2010), yet the recognition of DNA during tissue destruction is an integral part of the host immune and repair responses (Gregorio et al., 2010). Hence, effective management of self-tolerance and damage sensing appears to require the coordinated delivery of extracellular DNA to intracellular sites of recognition.

We were interested in defining cell surface receptor proteins that interact with extracellular nucleic acids. Here, we identify that the receptor for advanced glycation end-products (RAGE) binds directly to DNA and RNA and promotes their uptake into cells. RAGE can thereby sensitize cells to extracellular nucleic acids. A co-crystal structure of RAGE with DNA supports the concept that RAGE binds to nucleic acids via interaction with the charged sugar-phosphate backbones in a sequence-independent manner. While other receptors also play roles in nucleic acid recognition by immune cells, RAGE deficiency largely prevents an inflammatory response toward TLR9-stimulatory DNA in the lungs, suggesting that RAGE plays an important role in the control of immune responses to DNA in vivo.

\section{RESULTS}

RAGE promotes DNA binding and uptake by cells and interacts with DNA in a sequence-independent manner To address the role of RAGE in cellular responses to DNA, we generated cell lines expressing chimeric fluorescent RAGE driven by a tetracycline-inducible promoter. Uninduced cells did not show significant RAGE expression, and we observed only a low amount of DNA binding to the cells (Fig. 1 A). RAGEmCitrine expression was $\sim 100$-fold higher after promoter induction, and RAGE-expressing cells bound 10-100-fold more fluorescently labeled DNA compared with uninduced cells (Fig. 1 A). In addition, the amount of DNA binding correlated directly with the level of RAGE expression (Fig. 1 A). Notably, when incubated with fluorescently labeled DNA and visualized by confocal microscopy, cells expressing RAGE had visibly more DNA bound at the cell surface than cells not expressing RAGE (Fig. 1 B). These data suggested that RAGE interacts with and concentrates DNA on cell surfaces.

We next sought to identify the characteristics of RAGEbinding nucleic acids. Several structural classes of CpG oligonucleotides, which are known to activate TLR9 (Vollmer et al., 2004), bound to purified RAGE protein with low nanomolar apparent affinities (Fig. 1 C). Notably, oligodeoxynucleotides (ODN) bound RAGE in a sequence-independent manner, as even phosphodiester and phosphorothioate sugar-phosphate backbones without nucleotide bases bound to RAGE with apparent high affinities (Fig. 1 D). Similarly, deoxyribose was not required for nucleic acid interaction with RAGE, as both phosphodiester and phosphorothioated RNA oligonucleotides also bound in the low nanomolar range (Fig. 1 E). RAGE was able to bind ODN as short as $15 \mathrm{nt}$ in length (Fig. $1 \mathrm{~F}$ ), and we observed similar binding affinities for single-stranded (ss) and double-stranded (ds) forms of DNA (Fig. 1, G and H). These studies indicated that RAGE may bind to multiple forms of nucleic acids by interaction with the sugarphosphate backbones.

\section{RAGE binds DNA through electrostatic attractions with the backbone}

The RAGE extracellular region is composed of three structural domains named according to their homology with other members of the immunoglobulin superfamily: an N-terminal variable-type (V; or I-type; Koch et. al. 2010) domain, followed by two membrane-proximal constant-type domains (C1 and C2). The $\mathrm{V}$ and $\mathrm{C} 1$ domains are thought to form a single structural unit, which is separated from the C2 domain by a flexible linker region (Dattilo et al., 2007). To assess which part of RAGE interacts with DNA, we investigated DNA binding to recombinant $\mathrm{V}$ domain, $\mathrm{V}-\mathrm{C} 1$ domains, or $\mathrm{C} 1-\mathrm{C} 2$ domains, respectively. DNA binding was mediated primarily by the outermost $\mathrm{V}$ domain of RAGE (Fig. $2 \mathrm{~A}$ ), similar to what has been reported for binding of other RAGE ligands (Allmen et al., 2008; Dattilo et al., 2007; Park and Boyington, 2010). The C2 domain did not directly bind DNA in our assays (Fig. 2 A).

We next determined the crystal structures of the RAGE $\mathrm{V}-\mathrm{C} 1$ domain in complex with a 22-nt dsDNA derived from vaccinia virus genomic repeat sequences and a $22 \mathrm{mer} \mathrm{CpG}$ motif-containing dsDNA, at resolutions of 2.8 and $3.1 \AA$, respectively (Table 1). As the structures were essentially the same except for the two dsDNA sequences, this study will focus on the higher resolution $2.8-\AA$ structure. The double-stranded oligomer used for crystallization bound to RAGE in a manner similar to single-stranded CpG-B (Fig. $1 \mathrm{H}$ ). The structures were solved by molecular replacement using two previously published RAGEV-C1 domain structures (PDB accession nos. 3CJJ [Koch et al., 2010] and 3O3U [Park and Boyington, 2010]) as the search models. The structures revealed that the RAGE $\mathrm{V}-\mathrm{C} 1$ domain formed a homodimer with the dsDNA bound in a concave cradle near the dimer interface (Fig. 2 B). The two V-C1 monomers interacted with each other in a dyad configuration with their $\mathrm{V}$ domains located at the dimer interface (Fig. 2 B), creating an extensive positively charged pocket where 
A
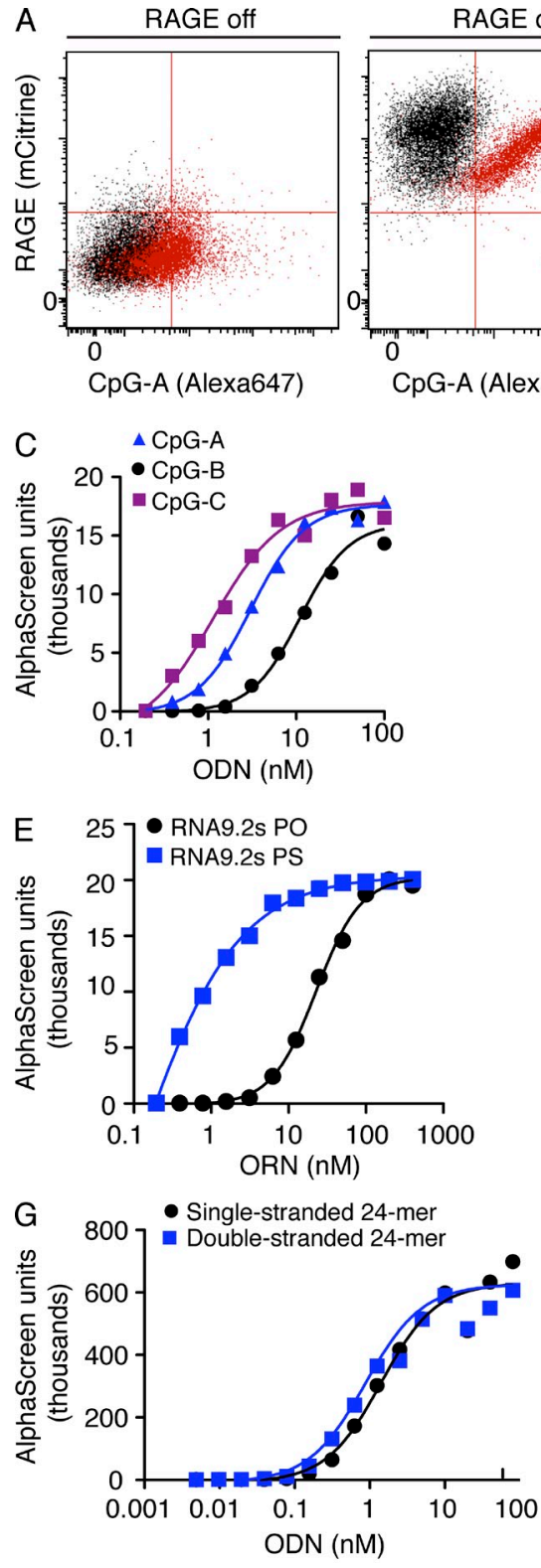

$B$
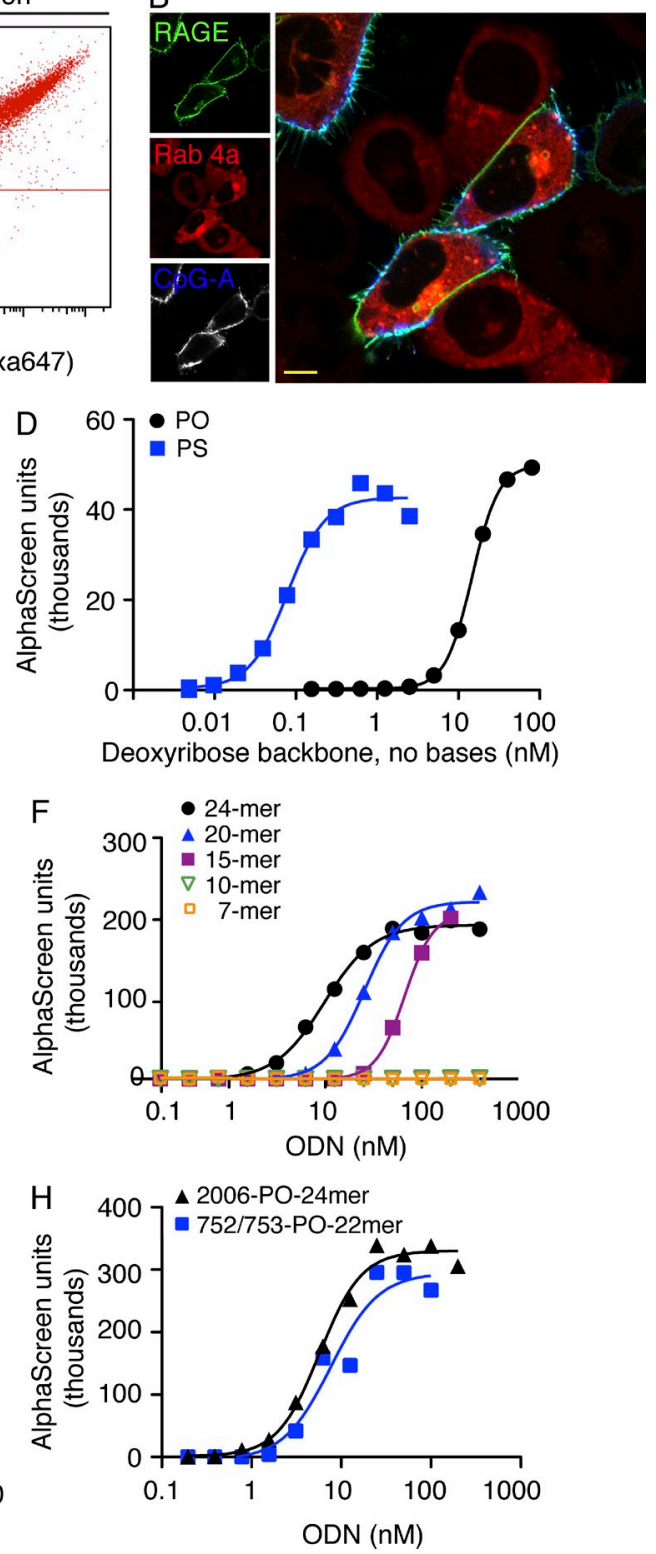

Figure 1. RAGE binds directly to nucleic acid ligands on the cell surface and promotes their uptake. (A) 293T cells expressing tetracycline-inducible RAGE-mCitrine were left uninduced (left, black population) or treated to induce RAGE expression (right, black population) and then incubated on ice with $1 \mu \mathrm{M}$ Alexa Fluor 647-labeled ODN 2336 (CpG-A, red populations), washed, and analyzed by flow cytometry. Data are representative of three similar experiments. (B) HeLa cells expressing Rab 4a-YFP (red) to stain cytoplasmic structures, with or without coexpression of RAGE-YFP (green), were incubated with $1 \mu \mathrm{M}$ Alexa Fluor 647-labeled ODN 2336 (CpG-A, blue) for 5 min. Unbound DNA was washed away and live cells were imaged by confocal microscopy. Image is representative of four similar experiments. Bar, $5 \mu \mathrm{m}$. (C-H) Ability of purified, His-tagged human RAGE extracellular domain to bind to biotinylated oligonucleotide ligands in solution was assessed by AlphaScreen homogenous binding assay. Indicated concentrations of biotinylated ODNs or oligoribonucleotides (ORN) were incubated with $40 \mathrm{nM}$ RAGE (V-C1-C2)-6His. PO, phosphodiester-linked deoxyribose backbone; PS, phosphorothioate-linked deoxyribose backbone. Data shown are representative of three or more independent experiments.
dsDNA binds. Excellent charge and shape complementarity were observed between the RAGE interface and the bound dsDNA. Each of the RAGEV-C1 domains engage both strands of the dsDNA through basic or hydrophilic residues from RAGE interacting with oxygen atoms of the DNA backbone and, in some cases, through coordinating water molecules. In contrast to sequence-specific DNA recognition by proteins such as transcription factors, the current structures showed no contact between RAGE and the nucleotide bases. Because the overall negative charge on the DNA molecule is determined by its phosphate backbone, we tested whether cationic polymer polyethyleneimine (PEI) could compete with RAGE for DNA binding. Our results showed that PEI could "mask" the negative charge of DNA and was sufficient to negate DNA-RAGE binding in vitro (Fig. 2 C), further highlighting the electrostatic nature of the recognition.
Close examination of the protein-DNA interaction surface indicated that $\sim 7$ positively charged residues on each $\mathrm{V}-\mathrm{C} 1$ unit were in close proximity to the negatively charged DNA backbone, spanning $\sim 17$ bp (Fig. 3, A and B), in agreement with our finding that the minimal length requirement for DNA binding was $\sim 15$ bases (Fig. 1 F). A total of $1300 \AA^{2}$ of solvent accessible surface area was buried at the RAGE-DNA interface. There are two DNA-binding patches on each RAGE molecule, hereafter referred to as "site 1" and "site 2" (Fig. 3 A). Site 1 is located entirely in the $\mathrm{V}$ domain near $\beta$-strand $\mathrm{B}(\beta \mathrm{B})$, and the connecting loops containing residues K37, K39, and K43, as well as K107 from $\beta$-strand G. Notably, residues K43 from molecule A and R29 from molecule B coordinate the same water molecule (w26) that forms a hydrogen bond with an oxygen of the DNA phosphate backbone (Fig. 3 A, top right). Site 2 is located at the juncture of the $\mathrm{V}$ and $\mathrm{C} 1$ domains, 

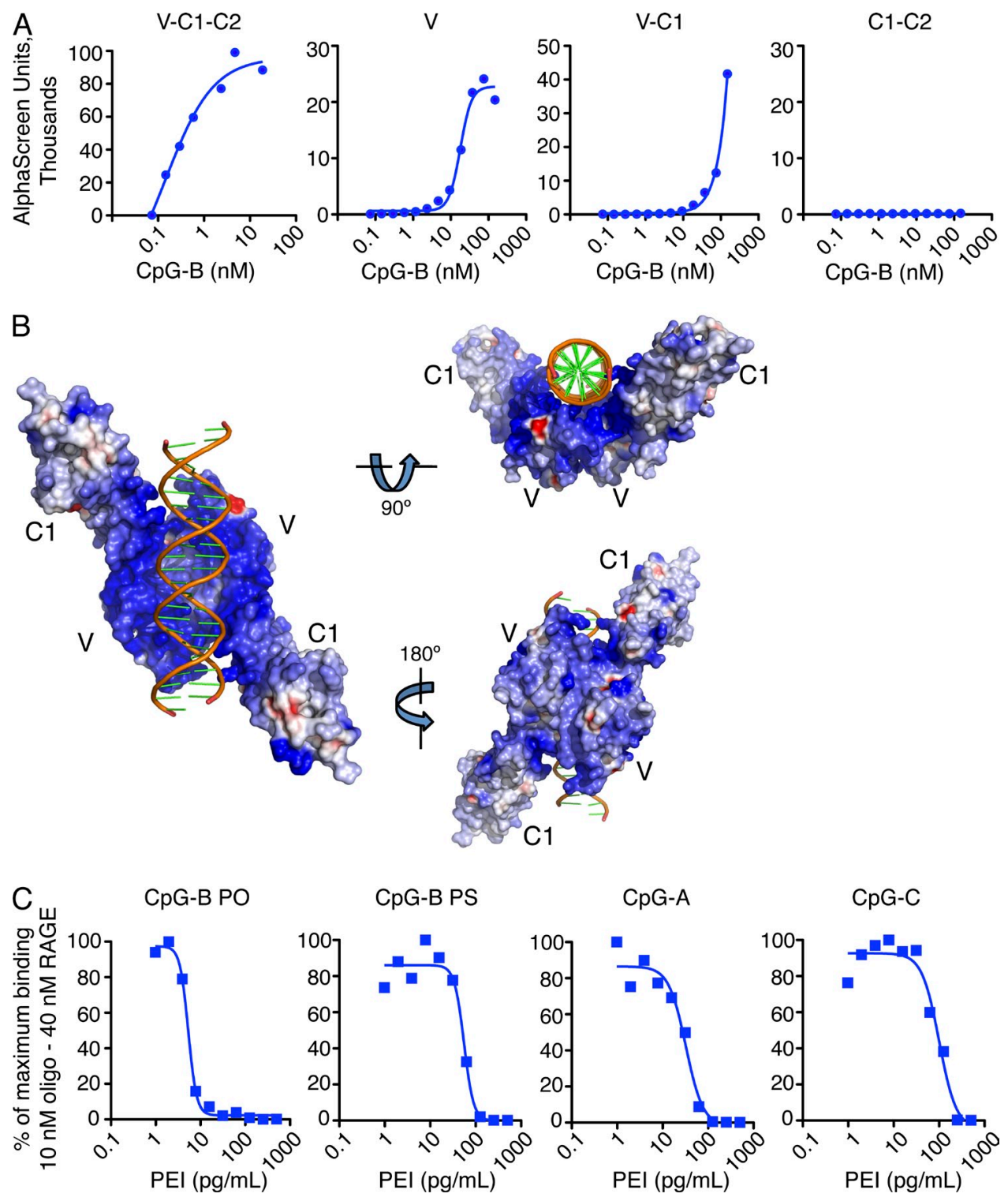

Figure 2. DNA interacts with a region of positive charges at the RAGE dimer interface. (A) Binding in solution of biotinylated ODN 2006 (CpG-B) to His-tagged full length human RAGE extracellular domain (V-C1-C2-His) or isolated structural domains was evaluated by AlphaScreen homogenous binding assay. Indicated concentrations of $\mathrm{CpG}-\mathrm{B}$ were incubated with $40 \mathrm{nM}$ RAGE. Data shown are from one experiment representative of three independent experiments. (B) Electrostatic charge surface of RAGE is shown on a scale of $-10 \mathrm{kT} / \mathrm{e}$ (red) to $+10 \mathrm{kT} / \mathrm{e}$ (blue) in three different orientations. The bound dsDNA is shown as an orange ribbon. (C) Polyethyleneimine (PEI) was incubated together with RAGE and biotinylated CpG DNA, as indicated, and RAGE-DNA interaction was assessed by AlphaScreen assay (PO, phosphodiester and PS, phosphorothioate backbones), CpG-A, and CpG-C. Data shown are from one experiment representative of two independent experiments.

and includes residues $\mathrm{R} 29$ at the $\mathrm{C}$ terminus of $\beta A, \mathrm{Y} 118$, and $\mathrm{K} 123$ of the V-C1 linker, and R216 and R218 of $\beta \mathrm{G}$ in the $\mathrm{C} 1$ domain. The amide group of R218 forms a direct hydrogen bond with a backbone oxygen of DNA (Fig. 3 A, bottom right). The footprints of the two RAGE molecules on the dsDNA are very similar, but not identical (Fig. 3 C), with the dsDNA switching its location of the major and minor grooves relative to the RAGE molecules, suggesting a rather flexible surface of the RAGE dimer that may be able to accommodate various forms of nucleic acids, such as ds or ss DNA and
RNA. This is consistent with the dominant presence of flexible lysine and arginine residues at the DNA-binding surface.

To probe the importance of the two DNA-binding regions, we generated mutations in key binding residues. Mutating either the site 1 (mutant 1 ) or site 2 (mutant 2) surfaces compromised DNA binding, whereas mutating three basic residues outside the DNA-binding surface (mutant 0 ) had no effect (Fig. 3 D). This confirmed that both site 1 and site 2 near the RAGE V-C1 dimer interface are critical for DNA binding. 
Table 1. X-ray crystallography data collection and refinement statistics

\begin{tabular}{|c|c|c|}
\hline Data collection & I $(752-753, W)$ & II (981-982, CpG) \\
\hline Spacegroup & $P 6_{1}$ & $\mathrm{P} 6_{1}$ \\
\hline Unit cell $(a, b, c)(\AA)$ & $79.12,79.12,224.04$ & $77.92,77.92,224.39$ \\
\hline$(\alpha, \beta, \gamma)\left(^{\circ}\right)$ & $90,90,120$ & $90,90,120$ \\
\hline Wavelength $(\AA)$ & 1.00 & 1.00 \\
\hline Resolution (last shell) (Å) & $50-2.80(2.85-2.80)$ & $50-3.10(3.15-3.10)$ \\
\hline $\begin{array}{l}\text { No of reflections (total/ } \\
\text { unique) }\end{array}$ & 154198/19330 & $138765 / 13817$ \\
\hline $\begin{array}{l}\text { Completeness (last shell) } \\
(\%)\end{array}$ & $99.4(96.6)^{a}$ & $99.0(85.6)^{\mathrm{a}}$ \\
\hline I/s(I) (last shell) & $14.49(1.97)^{a}$ & $16.10(1.97)^{a}$ \\
\hline $\mathrm{R}_{\text {merge }}$ (last shell) (\%) & $10.7(60.7)^{\mathrm{a}}$ & $14.0(65.3)^{\mathrm{a}}$ \\
\hline \multicolumn{3}{|l|}{ Refinement } \\
\hline Number of protein atoms & 3,267 & 3274 \\
\hline No. of DNA base pairs & 22 & 22 \\
\hline $\begin{array}{l}\text { No. of solvent/hetero- } \\
\text { atoms }\end{array}$ & 75 & 61 \\
\hline Rmsd bond lengths $(\AA)$ & 0.007 & 0.008 \\
\hline Rmsd bond angles $\left({ }^{\circ}\right)$ & 0.982 & 0.975 \\
\hline $\mathrm{R}_{\text {work }}(\%)^{\mathrm{c}}$ & 19.6 & 19.1 \\
\hline $\mathrm{R}_{\text {free }}(\%)^{\mathrm{d}}$ & 23.8 & 23.1 \\
\hline $\begin{array}{l}\text { Ramachandran plot } \\
\text { favored/disallowed (\%)e }\end{array}$ & $95.7 / 0$ & $95.7 / 0$ \\
\hline PDB accession code & $3 S 59$ & $3 S 58$ \\
\hline
\end{tabular}

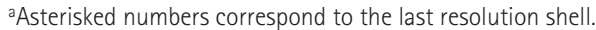

${ }^{b} R_{\text {merge }}=\Sigma_{h} \Sigma_{\mathrm{i}}\left|I_{i}(h)-<\right|(h)>\mid / \Sigma_{n} \Sigma_{\mathrm{i}} \mathrm{l}_{\mathrm{i}}(h)$, where $\mathrm{l}_{\mathrm{i}}(h)$ and $<\mid(h)>$ are the ith and mean measurement of the intensity of reflection $h$.

${ }^{C} R_{\text {work }}=\Sigma_{h}|| F_{\text {obs }}(h)|-| F_{\text {calc }}(h)||\left|\Sigma_{h}\right| F_{\text {obs }}(h) \mid$, where $F_{\text {obs }}(h)$ and $F_{\text {calc }}(h)$ are the observed and calculated structure factors, respectively. No I/r cutoff was applied. ${ }^{d} R_{\text {free }}$ is the $R$ value obtained for a test set of reflections consisting of a randomly selected $5 \%$ subset of the data set excluded from refinement.

eValues from Molprobity server (http://molprobity.biochem.duke.edu/).

No major conformational changes were observed in the RAGE V-C1 domains between the DNA-bound structures and those of the non-DNA bound forms (3CJJ [Park and Boyington, 2010] and 3O3U [Koch et al., 2010]; Fig. 4 A), consistent with the observation that the linkage between the V and C1 domains is fairly rigid (Dattilo et al., 2007) and is likely not modified by the binding of DNA ligands.

\section{Dimerization of the RAGE V-C1 domains}

A hydrophobic surface on the $\mathrm{V}$ domain is located at the center of the RAGE dimer interface in the current configuration we call "trans." It is composed of residues L79, P80, F85, P87, and A88 from the $\beta E$ strand and the connecting loops, plus $\mathrm{P} 33$ and V35 from the $\beta \mathrm{B}$ strand, and P45 and P46 from the $\beta B-\beta C$ loop (Fig. 4, A and B). The hydrophobic patch is surrounded by hydrophilic residues decorating the circumference of the dimer interface. A previous structure of RAGEV-C1 in the absence of bound DNA showed a crystallographic C1-C1 dimer that we call "cis," which is centered at a bound zinc ion (Koch et al., 2010). In comparison with the V domain-centered trans dimer interface, the cis dimer interface is hydrophilic and smaller in size. Unexpectedly, examination of the 3CJJ crystal lattice packing revealed that the trans dimers are also present in this crystal (Fig. 4 A), though the DNA-binding site is occluded by crystallographic symmetry mates. It is thus clear that the trans dimer formation is independent of DNA binding, and both the trans and the cis dimers can coexist as in the 3CJJ crystal. This is consistent with our observation that the most intense fluorescence of RAGE on the cell surface is located at the juncture of two adjacent cells (see Fig. 5 D), indicating that both trans and cis dimerization may be involved in the formation of the RAGE oligomers, with the cis and trans configurations mediating RAGE interaction on the same cell and adjacent cells, respectively.

The chemical nature of the trans dimerization interface, including a typical buried solvent-accessible surface area of $1,100 \AA^{2}$, together with the observations that RAGE V (Ostendorp et al., 2007),V-C1 (Koch et al., 2010), or V-C1-C2 (Srikrishna et al., 2010; Sárkány et al., 2011) domains spontaneously dimerize in solution, suggests that the V-domainmediated dimers are likely to be present under physiological conditions. RAGE molecules are highly conserved in both their DNA-binding sites and dimerization sites, and thus RAGE dimer binding to nucleic acids through electrostatic attraction may be a common mode of its function across different species.

DNA can induce formation of higher-order RAGE oligomers To confirm RAGE dimer formation in live cells, we subjected 293T cells expressing full-length human RAGE-mCitrine to treatment with the cell-impermeable cross-linking agent BS3, followed by cell lysis, protein denaturation, and gel electrophoresis. In the presence of cross-linker, higher molecular weight bands corresponding to dimers and higher-order oligomers can be detected in unstimulated cells (Fig. 5 A). To further explore the relationship of native RAGE dimers with DNA ligands, HEK293 cell lines stably expressing RAGE tagged with FRET donor (CFP or mCerulean) and acceptor (YFP or mCitrine) fluorophores were analyzed by both flow cytometry and confocal microscopy for sensitized emission Förster resonance energy transfer (FRET) between the fluorescent protein tags. A constitutive baseline energy transfer was observed in unstimulated cells (Fig. 5, B and D, top), supporting the idea that RAGE exists as a dimer in the absence of ligand. Addition of a CpG-B 72-mer (Fig. 5 C) or 24-mer oligonucleotide (Fig. 5 D, middle) did not alter energy transfer efficiency. Interestingly, however, the addition of a CpG-A 21-mer induced a dose-dependent increase in FRET efficiency (Fig. 5 C). CpG-A oligonucleotides are able to form large complexes in solution by virtue of G-tetrad association between poly-G tails on the ends of the ODN (Dapic et al., 2003). The induced increase in FRET is consistent with higher-order RAGE oligomer formation. In keeping with this observation, CpG-A DNA can be seen to induce aggregation of RAGE into clusters on the cell surface (Fig. 5 D, bottom), which is not observed in unstimulated cells or cells incubated with CpG-B (Fig. 5 D, top and middle). Notably, 

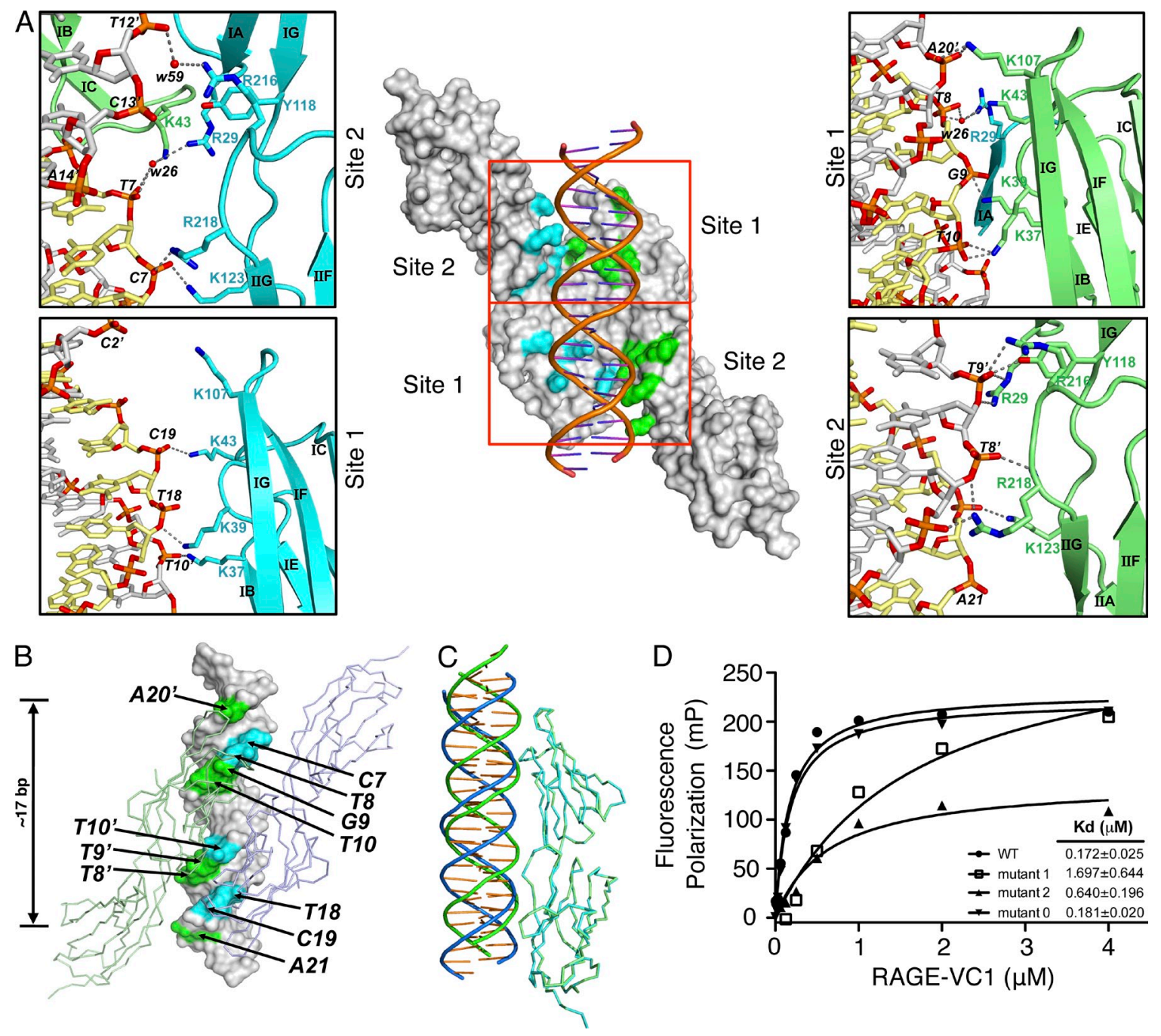

Figure 3. Details of the RAGE-DNA binding interface. (A) Surface representation (center) showing positively charged residues lining the RAGE dimer interface where DNA binding occurs. DNA-binding residues are colored green on one RAGE molecule ("A") and cyan on the other ("B"). Side panels show the molecular details of the two discrete binding sites, indicated by red boxes, for each RAGE V-C1 domain colored green and cyan. Hydrogen bonds are indicated with dotted lines, and the two strands of the dsDNA are colored silver and yellow, respectively. (B) Footprint of RAGE on dsDNA colored cyan and green for each of the V-C1 domains, as in A. (C) The two RAGE V-C1 molecules (cyan and green) in the crystal are superimposed with their bound dsDNA (blue and green), showing the switched positions for the major and minor grooves of the dsDNA in reference to the $V$-C1 domains. (D) Fluorescence polarization analysis of proteins containing mutations in site 1 (mutant 1) and site 2 (mutant 2) and mutations outside of the DNA-binding surface (mutant 0).

streptavidin complexation of a relatively long biotinylated ODN also increased FRET efficiency (Fig. 5 C). These findings suggest that whereas RAGE may bind DNA indiscriminately, larger ligand complexes can induce receptor reorganization on the cell surface.

\section{RAGE expression promotes DNA uptake by cells via the endosomal route}

Having established that RAGE and DNA interact at the cell surface, we sought to understand the functional consequences of this interaction. To assess whether interaction with RAGE influenced uptake of oligonucleotides into the cell, we evaluated the total uptake of fluorescent ODN in cells with or without
RAGE. In addition to the increased DNA binding to the cell surface observed previously, (Fig. 1, A and B; and Fig. 6 A, $4^{\circ} \mathrm{C}$ ), RAGE-expressing cells also showed a notable increase in total DNA uptake over a 30-min time period (Fig. 6 A, $37^{\circ} \mathrm{C}$ ), compared with cells not expressing RAGE. This effect was DNA specific, as binding and uptake of transferrin to its receptor (Fig. $6 \mathrm{~A}$ ) or the uptake of TLR2 ligand (not depicted) was not influenced by RAGE expression. Hence, RAGE increases the interaction of cells with nucleic acids and promotes their uptake.

CpG DNA in cell culture medium gains access to endosomal compartments, where it is able to interact with and stimulate Toll-like receptor 9 (TLR9), although the mechanism by 
A
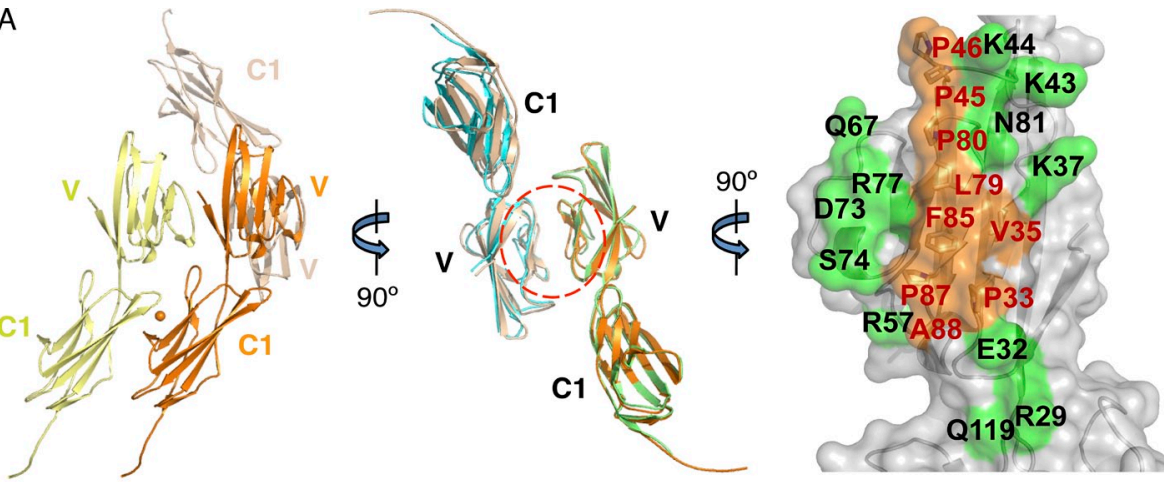

Figure 4. RAGE dimers form in two orientations. (A) Ribbon diagrams of the RAGE V-C1 dimerization interface. Left, RAGE V-C1 crystal packing in the non-DNA-bound form (3CJj; Koch et al., 2010), with V-C1 monomers colored yellow, orange, and wheat. The orange sphere indicates a zinc ion. Middle, wheat, and orange $\mathrm{V}-\mathrm{C} 1$ domains from the left superimposed onto the $\mathrm{V}-\mathrm{C} 1$ domains (cyan and green) in the current DNA-bound crystal structure. The dimer interface at the $\mathrm{V}$ domain (red circle) is represented in gray surface (right), with the hydrophobic and hydrophilic residues colored orange and green, respectively. (B) The RAGE dimer interface centered at the $V$ domain. Residues involved in RAGE dimerization are shown as sticks and colored cyan and green as the respective molecules. Water molecules are shown as red spheres and hydrogen bonds as dotted lines. The crystallographic dimer from $3 \mathrm{CJJ}$ is superimposed in our DNA-bound RAGE dimer structure in wheat and orange.

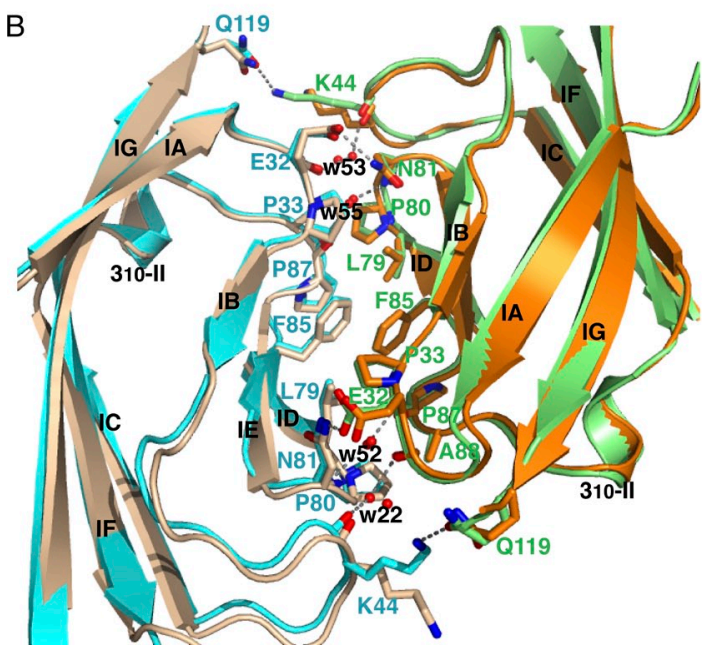

which this uptake occurs is unknown. Although cellular uptake of DNA is not strictly RAGE dependent (Fig. 6 A), we sought to evaluate the nature of the receptor-ligand association after surface binding. We stably expressed fluorescently tagged RAGE together with fluorescently tagged endosomal markers and assessed the binding and trafficking of DNA in live cells. Fluorescently labeled DNA was seen to associate with RAGE at the cell surface and traveled together with the receptor into both early and late endosomal compartments (Fig. 6, B and C). Although not all DNA-positive endosomes were RAGE-positive at a given time point, RAGE and DNA appeared to remain associated during uptake and progression through the endosomal network. Furthermore, our data suggest that this association may be more prevalent for CpG-A than CpG-B, which is consistent with the higher affinity of CpG-A observed in binding assays (Fig. 1 C). To more explicitly address whether RAGE might interact with TLR9 after uptake, we assessed the ability of TLR9 to co-immunoprecipitate RAGE from lysates of cells before and after exposure to TLR9-stimulatory DNA. We saw that TLR9 associated with a relatively small but notable amount of RAGE in unstimulated cells and that this association was enhanced after stimulation of the cells with CpG DNA (Fig. 6 D). This supports the idea that RAGE-associated DNA is delivered to TLR9containing compartments and suggests that these receptors may interact simultaneously with a common ligand.

\section{RAGE increases TLR9-dependent responses to suboptimal DNA stimuli}

Both RAGE and TLR9 have been shown to activate the NF- $\kappa \mathrm{B}$ family of transcription factors upon ligation of stimulatory ligands (Chuang and Ulevitch, 2000; Yan et al., 1994). To assess the ability of CpG DNA to activate RAGE signaling, we used an HEK cell line expressing a luciferase reporter gene under the control of an NF- $\mathrm{KB}$-inducible promoter. No change in reporter activation was observed upon DNA stimulation when these cells overexpressed RAGE alone (unpublished data). To evaluate the ability of RAGE to contribute to TLR9-dependent responses to DNA, cell lines stably expressing either TLR9 or TLR7 were transiently transfected with the NF- $\mathrm{KB}$ luciferase reporter and either RAGE or RAGE lacking the putative cytoplasmic signaling domain (RAGE-dC). Both cell lines expressed similar levels of the two RAGE constructs (Fig. $7 \mathrm{~A}$ ) and showed similar responses to control stimuli (Fig. 7 A, bar graphs). CpG-B oligonucleotides preferentially activate the transcription factor NF- $\mathrm{\kappa B}$ downstream of TLR 9 in many cell types, whereas CpG-A ODNs optimally induce type I interferons and do not induce a strong NF- $\kappa \mathrm{B}$ response. CpG-B activated NF- $\mathrm{KB}$ in a dose-responsive manner in cells expressing TLR9 without RAGE, and this activation was notably enhanced when cells coexpressed RAGE or RAGE-dC (Fig. 7 A, top). This RAGE-dependent enhancement was specific for DNA activation of TLR9, as no 

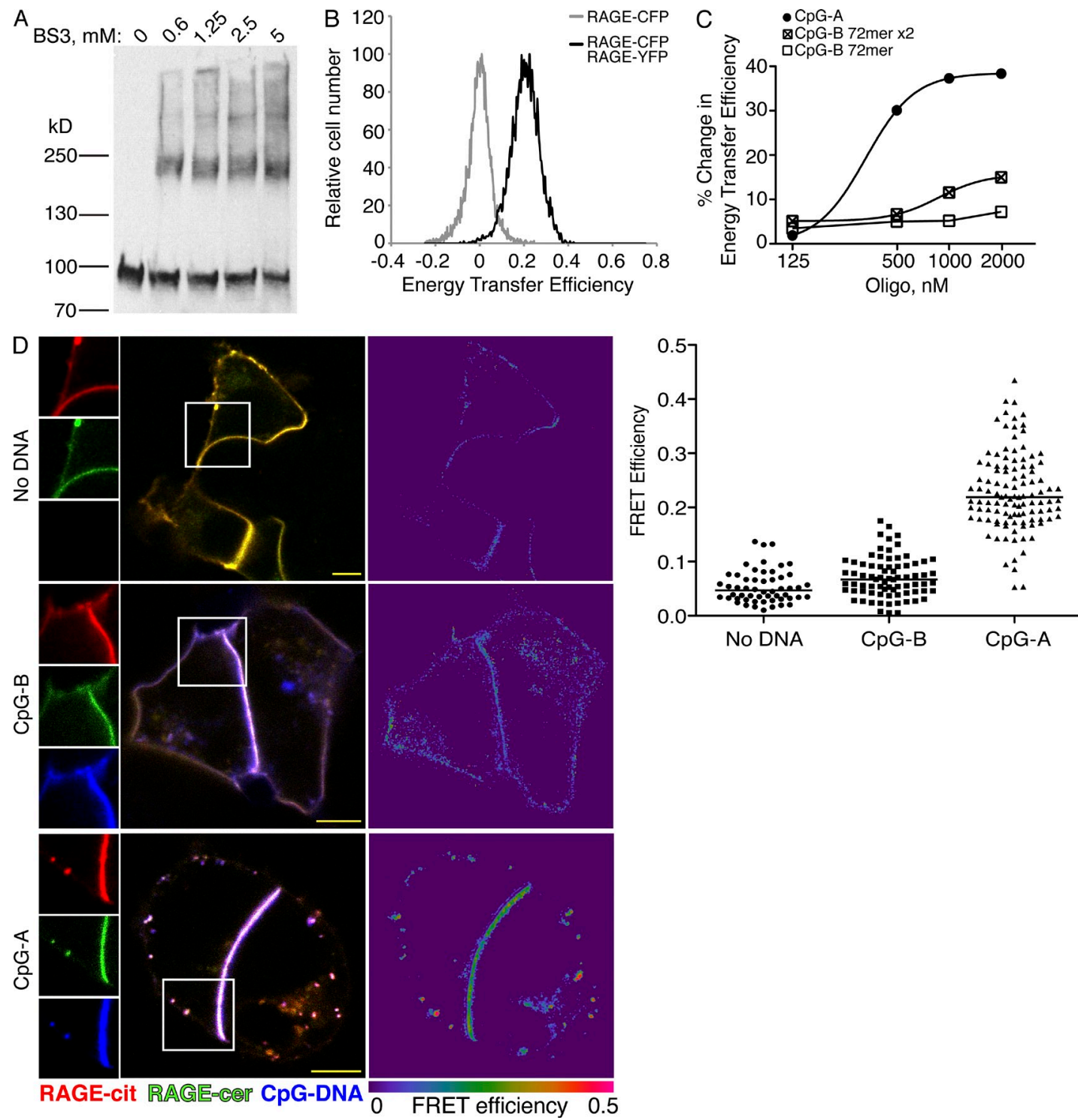

Figure 5. Constitutive RAGE dimers form higher order oligomers in the presence of complex DNA ligands. (A) 293T cells expressing RAGE-mCitrine were incubated with or without the amine-reactive cross-linking agent BS3 before immunoblot for the mCitrine tag. Data shown are representative of three independent experiments. (B) HEK293 cells coexpressing RAGE-CFP and RAGE-YFP were analyzed for FRET by flow cytometry. Cells show detectable baseline FRET (black histogram) in the absence of ligand. Cells expressing only RAGE-CFP (FRET-negative, gray histogram) are shown for reference. Data shown are representative of more than five independent experiments. (C) Cells from (B) were incubated with the indicated concentrations of oligonucleotides and analyzed for FRET by flow cytometry. Graph shows the percent increase in FRET signal over baseline FRET. "x2" indicates biotinylated ODN complexed with streptavidin in a 2:1 ratio. Data are representative of two independent experiments. (D) HEK293 cells coexpressing RAGE-mCerulean and RAGE-mCitrine were incubated for $30 \mathrm{~min}$ at $37^{\circ} \mathrm{C}$ with Alexa Fluor 647 -labeled CpG-A or CpG-B and analyzed for FRET by confocal microscopy. Images are representative of four independent experiments. Bars, $5 \mu \mathrm{m}$. Data in right panel are shown as mean and distribution of quantified cells from the representative experiment.

NF- $\mathrm{KB}$ activation was observed in cells coexpressing RAGE and TLR7 (Fig. 7 A, bottom). To further evaluate the role of the signaling domain in RAGE-dependent responses to DNA, we studied $293 \mathrm{~T}$ cells expressing RAGE or RAGE-dC under the control of a tetracycline-inducible promoter. Cells expressing full-length or tail-truncated RAGE internalized more CpG-A and CpG-B over a 2-h period than their uninduced counterparts (Fig. 7 B), and both forms of RAGE showed similar levels of association with CpG DNA by confocal microscopy. Collectively, these data demonstrate that RAGE enhances NF- $\kappa \mathrm{B}$ activation by CpG-DNA in a TLR9-dependent fashion, and that RAGE promotes increased delivery of ligand to TLR9 in this system, rather than activating the NF- $\mathrm{KB}$ pathway through its own signaling domain.

We next sought to understand whether RAGE could similarly affect responses to autoimmune disease-relevant nucleic 

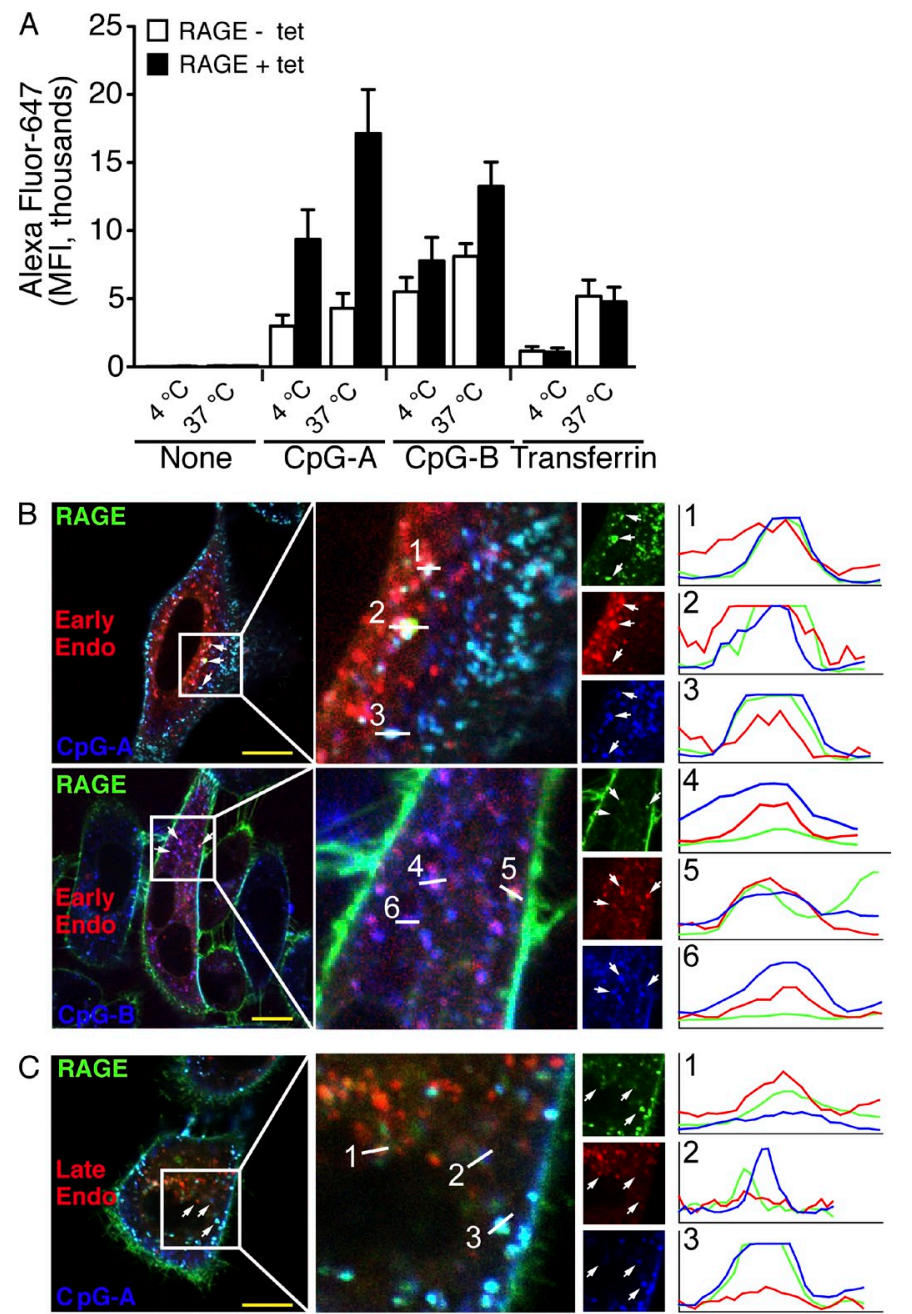

6
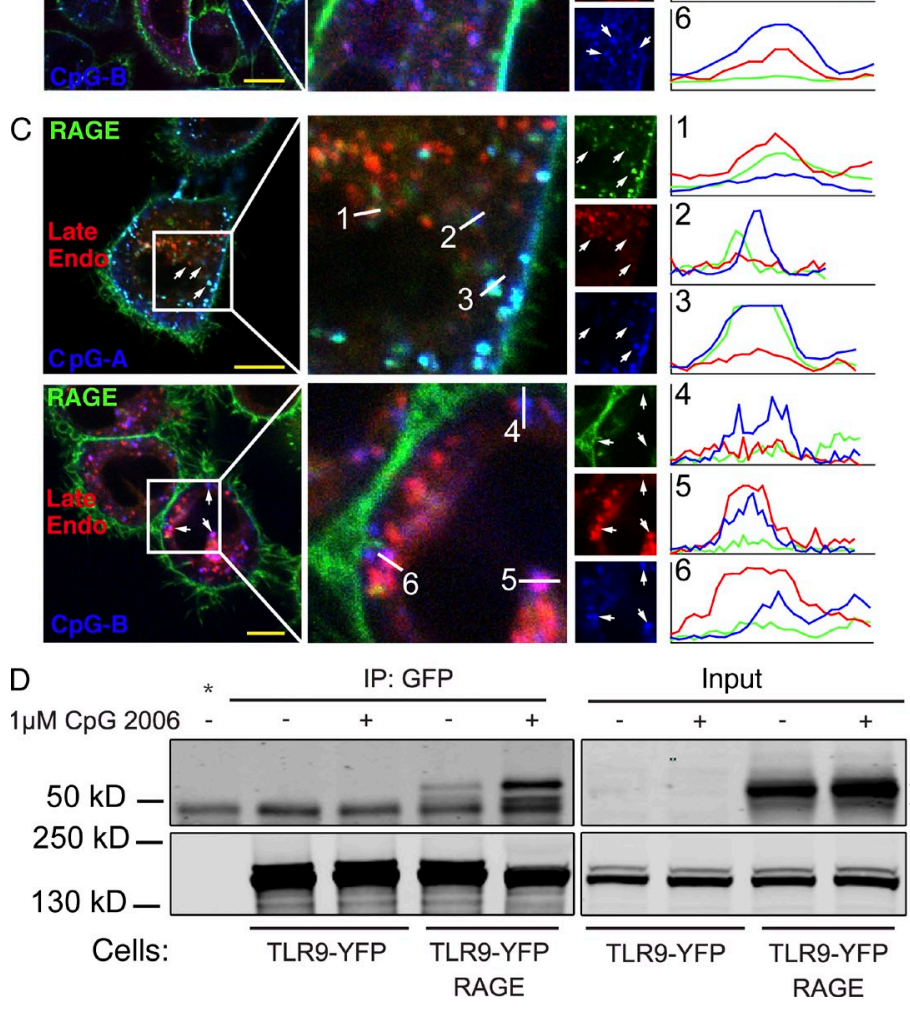

Figure 6. RAGE promotes cellular DNA uptake into endosomes. (A) 293T cells expressing tetracycline-inducible RAGE-mCitrine were induced overnight (black bars) or left untreated (white bars), and then incubated with $1 \mu$ M Alexa Fluor 647-labeled ODN 2336 (CpG-A), ODN 2006 (CpG-B) or transferrin for $30 \mathrm{~min}$, either on ice or at $37^{\circ} \mathrm{C}$ to permit receptor-mediated uptake. Cells were washed and fluorescence was assessed by flow cytometry. Data are from one experiment representative of three. (B and C) HeLa cells expressing RAGE-CFP (green) and the early endosome protein Rab 5a-RFP (B; red) or the late endosome protein Rab 9a-YFP ( $\mathrm{C}$; red) were incubated with $1 \mu \mathrm{M}$ Alexa Fluor 647labeled CpG-A or CpG-B (blue) for 5 min, washed to remove unbound DNA, and then incubated for $20 \mathrm{~min}$ at $37^{\circ} \mathrm{C}$ before analysis by confocal microscopy. Line analyses show pixel intensity (y axis) along the indicated line ( $x$ axis) in each of the three fluorescence channels. Images are representative of 4-5 quantified fields in this experiment, and a total of four independent imaging experiments. Bars, 5 um. (D) Cells expressing TLR9YFP with or without coexpressed RAGE were stimulated with CpG-B for $1 \mathrm{~h}$ or left untreated and TLR9 was subsequently immunoprecipitated using an anti-GFP antibody. TLR9 and coimmunoprecipitated RAGE were assessed by Western blot using specific antibodies. Cell lysates were controlled for TLR9 and RAGE total expression (Input). ${ }^{*}$ indicates an IP condition with beads but no antibody, to identify nonspecific binding; ns indicates a nonspecific band. Data are representative of three similar experiments. acids such as mammalian DNA. For this, the luciferase reporter cell line was co-cultured with immortalized murine bone marrow-derived macrophages, which were treated with silica to induce macrophage cell death and nucleic acid release (Hornung et al., 2008). Indeed, the presence of silicakilled macrophages in co-culture activated NF- $\mathrm{BB}$ in the luciferase reporter cell line, and this activation increased in cells expressing RAGE (Fig. 8 A, left, closed bars). When the extracellular DNA and RNA content was removed by addition of benzonase to the supernatants, the RAGE-mediated increase in $\mathrm{NF}-\kappa \mathrm{B}$ activity in the reporter cells was reduced to background levels (Fig. $8 \mathrm{~A}$, left, open bars). This indicates that the enhancement of TLR9 activation by RAGE is largely caused by recognition of nucleic acids, rather than 

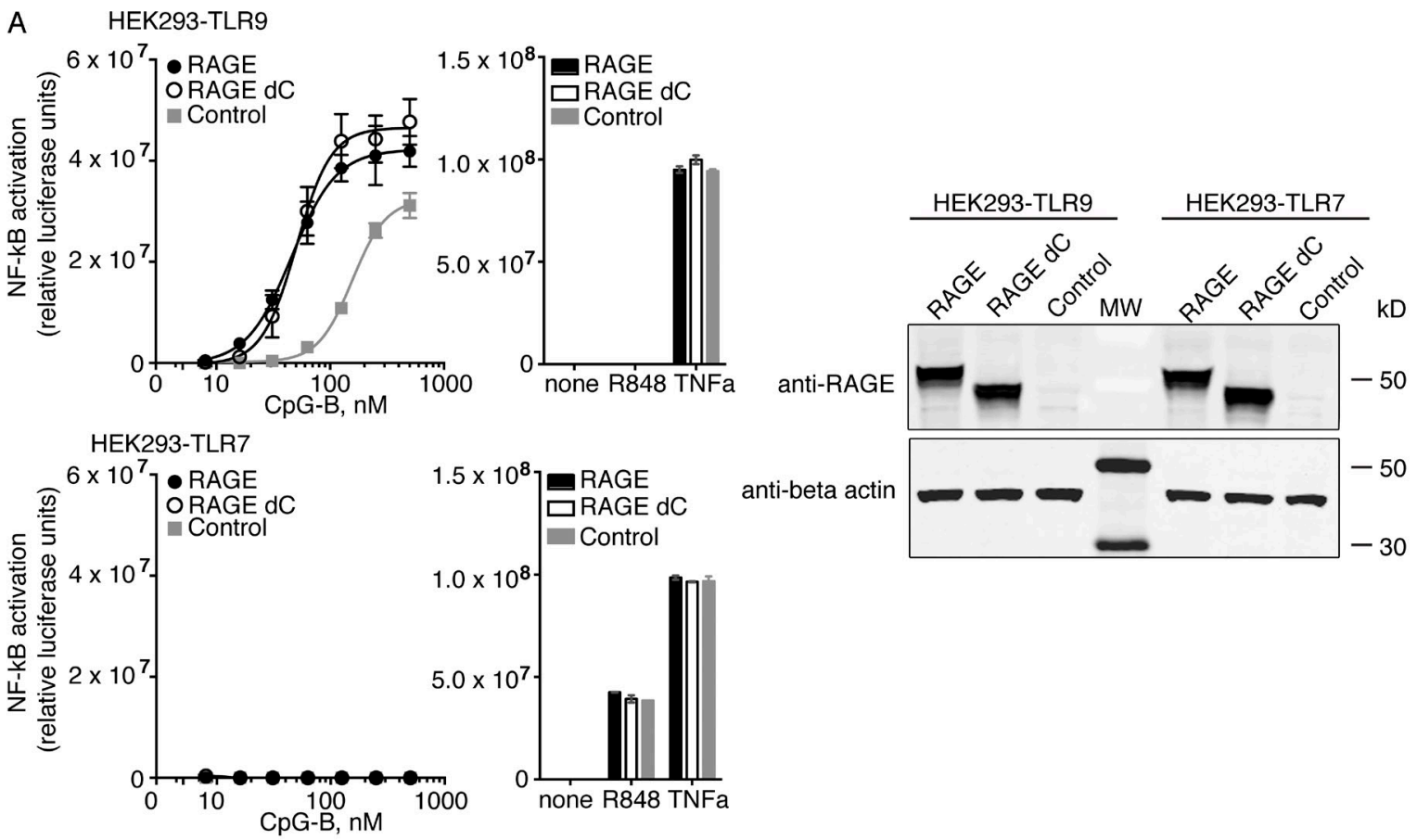

B CpG-B
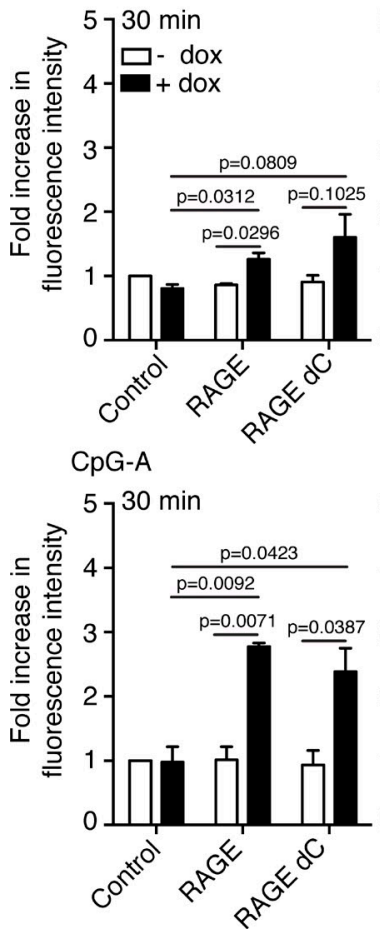

C RAGE
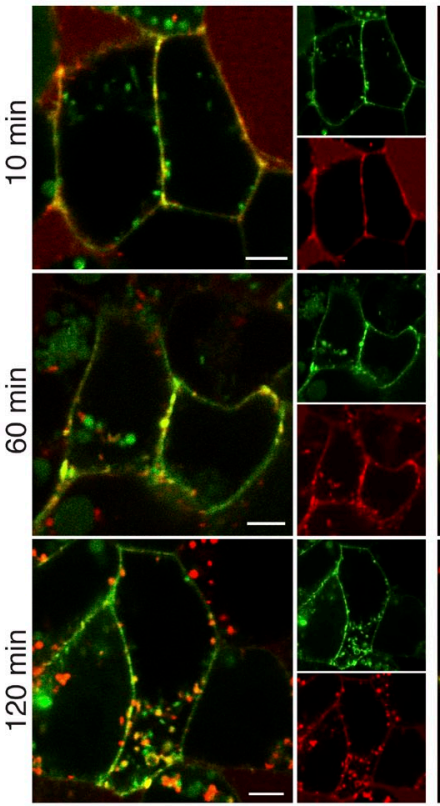

RAGE

CpG-A
RAGE dC

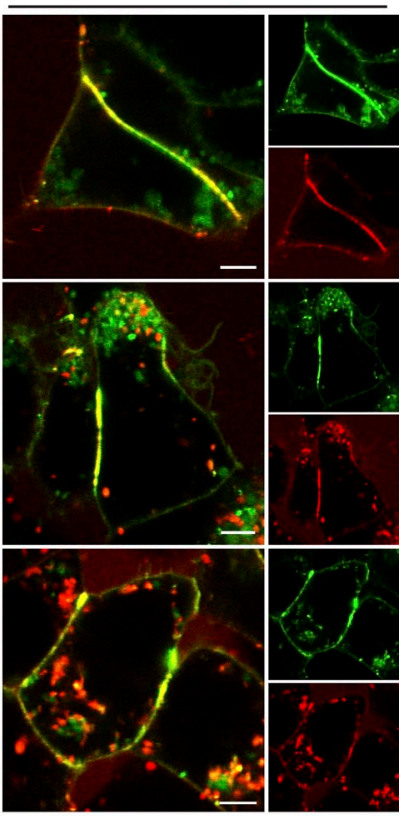

RAGE dC CpG-A

Figure 7. RAGE increases TLR9-dependent NF-кB activation in response to DNA ligands. (A) HEK293 cells stably expressing TLR9 or TLR7 were transiently transfected with an NF-kB-driven luciferase reporter and wild-type RAGE, RAGE lacking the cytoplasmic domain (RAGE dC), or empty vector (control). Cells were stimulated as indicated for $20 \mathrm{~h}$ before luciferase assay readout. Data are shown as mean \pm SEM for duplicate samples and are representative of four similar experiments. Expression levels of RAGE and RAGE dC in concurrently transfected, unstimulated cells was assessed by Western blot (right). (B) 293T cells expressing tetracycline-inducible constructs of mCitrine-tagged RAGE, RAGE dC, or empty vector control were left untreated (-dox) or treated with doxycycline to induce construct expression (+dox). Cells were treated for the indicated times with fluorescently labeled CpG-A or CpG-B and washed to remove excess oligonucleotides, and fluorescence was analyzed by flow cytometry. Plots show background-corrected median fluorescence intensities corresponding to labeled $\mathrm{CpG}$, normalized to the signal from untreated HEK 293T cells without exogenous RAGE-expression. Error bars represent SEM for two independent experiments. P-value indicates significance in unpaired Student's $t$ test. (C) Cells from B were induced with doxycycline and treated with fluorescently labeled CpG-A, and localization of ligand and receptor was assessed at the indicated time points. Data shown are representative of two independent experiments. Bars, $5 \mu \mathrm{m}$. 
other components of cell debris. In effect, DNA from dying macrophages appeared to interact with fluorescently tagged RAGE when co-cultured cells were imaged by confocal microscopy (Fig. 8 B) and RAGE expression led to increased uptake of DNA from the co-cultured dying cells (not depicted). Collectively, the data in Figs. 7 and 8 suggest that RAGE effectively delivers DNA into the cellular compartments in which TLR9 is activated and that expression of RAGE sensitizes cells to both synthetic and endogenous nucleic acids present in the extracellular environment.

\section{RAGE-deficient mice have impaired inflammatory responses to DNA in the lung}

Given its ability to potentiate NF- $\mathrm{KB}$ activation in cultured cells, we sought to assess the role of RAGE in proinflammatory responses to DNA in vivo. Although RAGE has been reported to be expressed on several types of mammalian leukocytes (Brett et al., 1993; Dumitriu et al., 2007; Moser et al., 2007), RAGE is most highly expressed in mammalian lung epithelia (Demling et al., 2006; Buckley and Ehrhardt, 2010; this study). We therefore hypothesized that RAGE might participate in immune recognition of DNA in the airways. To address this possibility, we intranasally administered a low dose of CpG-B DNA to C57BL/6 wild-type or RAGE deficient $\left(\right.$ ager $\left.^{-1-}\right)$ mice and evaluated inflammatory parameters in the lung at $24 \mathrm{~h}$ after DNA exposure. Wild-type mice mounted a strong inflammatory response to CpG-B DNA, characterized by a significant increase in neutrophils in bronchoalveolar lavage (BAL) fluid, and increased expression of the neutrophil chemoattractant LPS-induced CXC chemokine (LIX; Fig. 9 A). Strikingly, RAGE-deficient animals showed significantly lower neutrophil influx and LIX levels indistinguishable from PBS-treated control animals (Fig. 9 A). Histological analysis of lung tissue revealed marked perivascular and peribronchiolar leukocyte influx in wild-type mice that was notably reduced in RAGE-deficient mice (Fig. 9 B). Analysis of cytokines in the BAL fluid revealed significantly reduced production of IFN- $\gamma$, IL-6, TNF, and IL-12 p70 in RAGE-deficient animals as compared with the wild type (Fig. 9 C). IL-1 $\beta$ and IFN- $\alpha$, cytokines whose production is not directly activated by $\mathrm{NF}-\kappa \mathrm{B}$, were also up-regulated in wild-type but not RAGE-deficient mice after CpG-B exposure, suggesting a broader role of RAGE in systemic inflammation. When wild-type mice were similarly challenged with CpG-A there were notable levels of IFN- $\alpha$ in the airways, consistent with the typical TLR9-based response to CpG-A, and this effect was significantly attenuated in RAGE deficient mice (Fig. 9 D). RAGE deficient mice also showed lower levels of the proinflammatory cytokines IFN- $\gamma$, IL-12 p70 and TNF, compared with wild-type mice (Fig. 9 D). RAGE-induced signaling pathways are thought to vary according to cell type (Ramasamy et al., 2009) and the mechanisms by which RAGE influences the immune response in vivo are likely to be complex and multivariate. We note that soluble isoforms of RAGE (sRAGE) also exist in vivo (Kalea et al., 2009). We found no notable changes in sRAGE levels in wild-type mice after intranasal CpG DNA administration (data not depicted); however, the absence of sRAGE may also be a factor in the knockout phenotype. Although these complexities remain to be elucidated, the data presented here indicate that RAGE expression plays an important role in mediating inflammatory response to immunostimulatory DNA in vivo, and particularly, in the lung.

\section{DISCUSSION}

RAGE has been implicated in initiating and perpetuating inflammatory responses upon engagement of glycated proteins, amyloid- $\beta$ fibrils, S100 proteins, and HMGB1 (Hofmann et al., 1999; Hudson et al., 2008; Huttunen et al., 1999; Lander et al.,
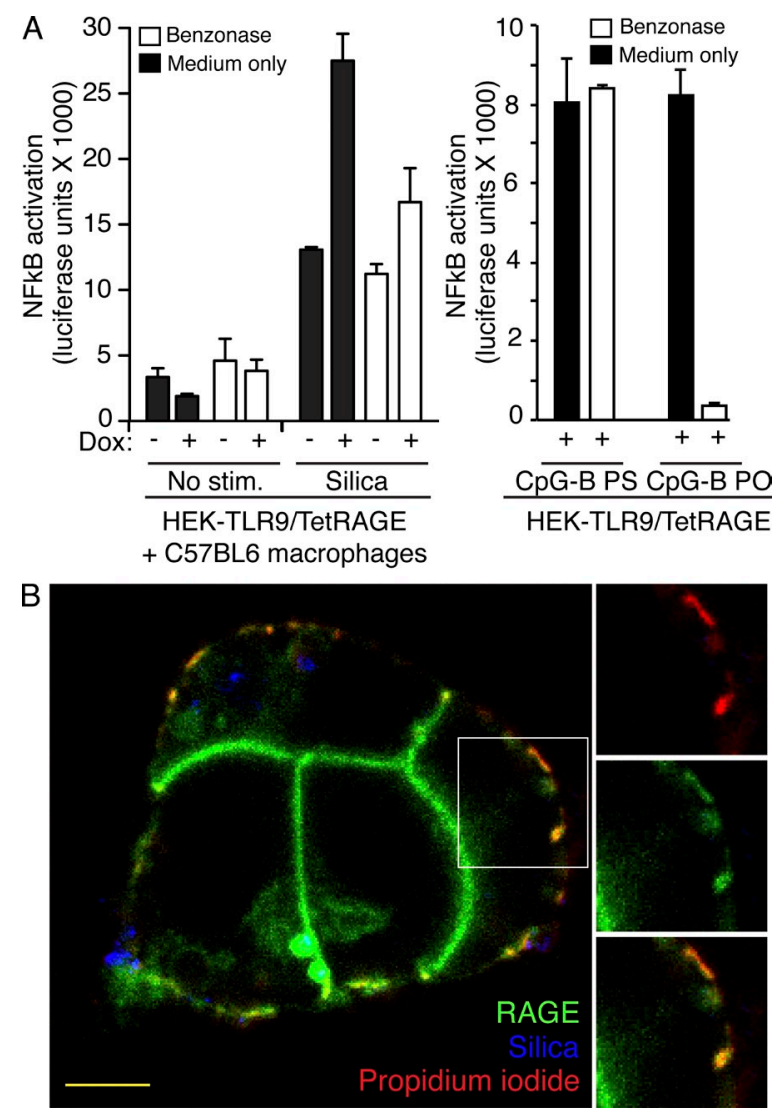

Figure 8. RAGE increases TLR9-dependent NF- $\mathrm{B}$ activation in response to mammalian nucleic acids. (A) HEK293 cells expressing TLR9 and tetracycline-inducible RAGE-mCerulean ELAM-luc reporter were cultured with or without doxycycline to induce RAGE expression, together with murine bone marrow-derived macrophages. Co-cultures were left unstimulated or stimulated with silica crystals to induce macrophage cell death. Degradation of the phosphodiester (PO) CpG-B DNA stimulus served as a positive control for benzonase activity; phosphorothioated (PS) DNA is resistant to nuclease digestion and benzonase treatment did not affect its ability to activate NF- $\kappa$ B through TLR9. Data are shown as mean with SEM for triplicate samples and are representative of three independent experiments. (B) Co-cultured cells from A were incubated with silica for $6 \mathrm{~h}$, stained with propidium iodide to label DNA from dead cells, and imaged by confocal microscopy. Silica was visualized using a reflection microscopy technique (Hornung et al., 2008). Bars, 5 m. 

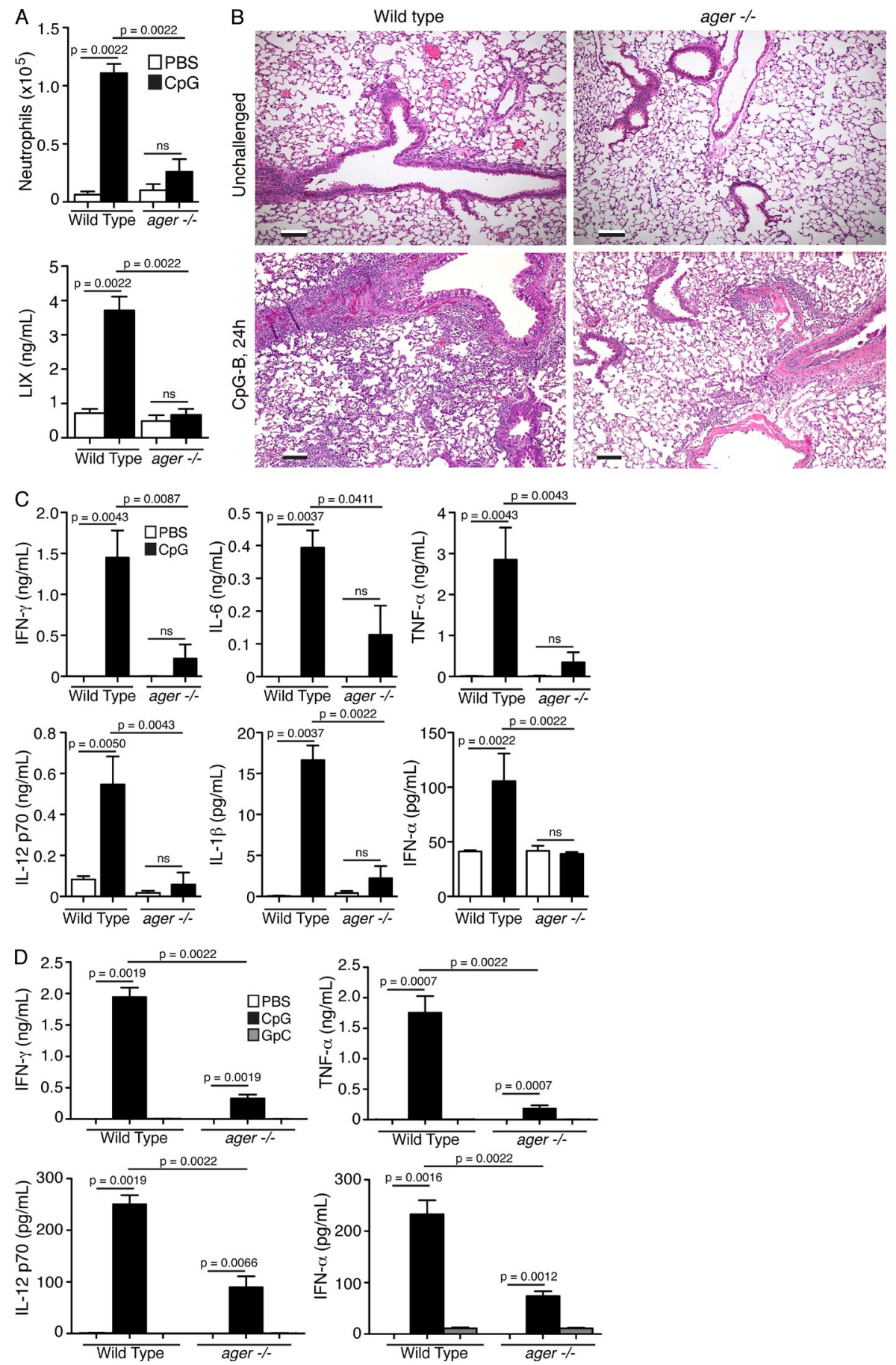

Figure 9. RAGE mediates DNA-induced pulmonary inflammation in vivo. $(A-C)$ C57BL/6 wild-type or RAGE-deficient mice were administered PBS with or without $5 \mu \mathrm{g}$ CpG-B via the intranasal route and analyzed $24 \mathrm{~h}$ later for signs of pulmonary inflammation. $n=6$ mice per group. Data shown are from one of two independent experiments with similar results. (A) Neutrophil cell number (top), and LIX concentration (bottom) were determined in bronchoalveolar lavage fluid. (B) Representative hematoxylin and eosinstained paraffin sections of lung tissue from wild-type and RAGE-deficient (ager- ${ }^{--}$) mice, at 10x magnification. Bars, $100 \mu \mathrm{m}$. (C) Cytokine concentrations in BAL fluid were determined by ELISA. (D) C57BL/6 wild-type or RAGE-deficient mice were administered PBS with or without $50 \mu \mathrm{g} \mathrm{CpG-A}$ (or control $\mathrm{GpC}-\mathrm{A}$ ) via the intranasal route and analyzed $24 \mathrm{~h}$ later for signs of pulmonary inflammation. $n=8(\mathrm{PBS}, \mathrm{GpC})$ or $6(\mathrm{CpG})$ mice per group. Cytokine concentrations in BAL fluid were determined by ELISA. (A, $C$, and D) Data are presented as mean with SEM. P-value indicates significance in the nonparametric Mann-Whitney $U$ test; $n s=$ differences are not significant.
1997). Our work characterizes RAGE as a cell surface receptor for nucleic acids that influences the concentration threshold at which DNA activates inflammatory responses in vitro and in vivo. This cellular thresholding toward nucleic acids may be of importance to carefully balancing the ubiquitous presence of self-nucleic acids with the necessity for swift and decisive responses toward microbially derived nucleic acids. Whether by modulating uptake or by generating a regulatory signal, RAGE critically influences cellular responses toward self-derived nucleic acids or DNA sequences that mimic microbial DNA, and as such, may determine the strength and duration of an immune response to nucleic acids.

It has also been proposed that complexes containing multiple RAGE ligands or RAGE ligated simultaneously with other receptors may provide a "symphony" of signals that allow the immune system to distinguish between distinct types of danger, and to appropriately adjust the immune response to nucleic acids (Krieg, 2007). Such synergy between multiple 
RAGE ligands may help to reconcile our observation of a direct RAGE-DNA interaction with published data indicating that HMGB proteins, also RAGE ligands, are important for TLR activation by nucleic acids (Yanai et al., 2009). Our previous work suggested that a DNA-HMGB1 complex was more effective at activating plasmacytoid dendritic cells than HMGB1 alone (Tian et al., 2007). Judging from the RAGE-DNA complex structure presented here, it is clear that HMGB1 is not essential for the RAGE-DNA binding event, as DNA can directly bind to RAGE in the absence of HMGB1. However, our data also demonstrate that structured DNAs have higher affinities to RAGE, and that these types of DNA induce receptor superclustering. This may alter the rate at which they traffic through the endosomal network in complex with RAGE. HMGB1 is commonly present in mammalian sera and is induced during tissue damage. Thus, in agreement with our previous work, DNA complexation by HMGB1 would be expected to change the DNA-binding properties to RAGE and modify DNA trafficking. Previous work suggests that trafficking of nucleic acids is regulated and influenced by both the ligand (Honda et al., 2005) and cellular factors (Blasius et al., 2010; Sasai et al., 2010). By this logic, HMGB1 may influence the subcellular site of interaction with the signaling receptor, thus altering the relative activation of $N F-\kappa B$ and type-I interferon signaling pathways downstream of TLR9, a hypothesis that remains to be tested. With or without the help of cofactors like HMGB1, specificity for distinct nucleic acid sequences or structures is a hallmark of many known nucleic acid sensors. Unmethylated $\mathrm{CpG}$ dinucleotide motifs (Hartmann et al., 2000; Hemmi et al., 2000) promote activation of TLR9, and such a $\mathrm{CpG}$ sequence preference has also been reported for DNA binding to RAGE (Ruan et al., 2010). However, this sequence preference appears to be restricted to the nonnative form of phosphorothioate backbone, and TLR 9 responses to the native phosphodiester DNA are sequence-independent (Haas et al., 2008). In agreement, our data strongly suggest that the DNA-RAGE interaction occurs irrespective of nucleotide sequence, and that RAGE serves to sample any type of "naked" extracellular nucleic acid. The RAGE-DNA complex structures illustrate that RAGE interacts with negatively charged phosphates of the nucleic acid backbone, and this is corroborated by binding of base-free ribose and deoxyribose phosphate backbones to RAGE in solution. To our knowledge, this is the first structural analysis of RAGE co-crystallized with nucleic acids, and the DNA-RAGE interface supports the charge-based binding modality that has been inferred for AGE (Park and Boyington, 2010), HMGB1 (Banerjee et al., 2010), S100b (Koch et al., 2010), and, most recently, heparan sulfate (Xu et al., 2013). Thus, RAGE may engage a variety of acidic or negatively charged ligands through electrostatic attractions similar to those detailed here.

We note with interest that most characterized RAGE ligands are either released during cell stress (S100 proteins, HMGB1, and nucleic acids), or generated during prolonged hyperglycemia and inflammation (AGE, amyloid $\beta$, and serum amyloid A; Sims et al., 2010). At the same time, RAGE expression itself is driven by inflammation, as the gene possesses an NF- $\mathrm{kB}-$ responsive promoter (Li and Schmidt, 1997). Hence, the combination of induced receptor expression and appearance of RAGE ligands specifically at times of inflammation may serve to lower thresholds and amplify inflammatory responses in a timely manner. Moreover, the propensity of many RAGE ligands to interact with themselves (S100 proteins; Ostendorp et al., 2007) or with one another (nucleic acids and HMGB1; Tian et al., 2007) to form sizable complexes, appears to increase ligand-receptor affinity and allow for simultaneous detection of danger signals with nucleic acids released from microbes. Thus, RAGE is likely to integrate combinations of inflammatory stimuli, and drive appropriately adjusted immune responses. The activity of RAGE is also regulated by concentration and metal ion-dependent cis- or trans- homodimerization (Koch et al., 2010; Sárkány et al., 2011) and the soluble RAGE form has been shown to interfere with RAGE dimerization and signaling (Hofmann et al., 1999; Bierhaus et al., 2001). Thus, fine-tuning of RAGE activation is likely an important mechanism for timely detection of microbes and sterile tissue damage. However, increased autoantibody complexation of nucleic acids and other RAGE ligands during autoimmune diseases, as well as numerous disease phenotypes linked toRAGEinanimalmodels (Yan etal.,2009), suggest that RAGEmediated augmentation of inflammation can be dysregulated in immune pathologies and RAGE, therefore, represents an attractive target for pharmacological intervention.

\section{MATERIALS AND METHODS}

ODNs. ODN sequences and sources are listed in Table S1.

Cell lines. Cell lines in the HEK293, 293T, HeLa, and U373 backgrounds were produced using retro- or lentiviral transduction with human RAGE C-terminally fused to fluorescent protein tags, as indicated in the text and figure legends. We note that, although $293 \mathrm{~T}$ cells have been reported to express RAGE (Zong et al., 2010), no endogenous RAGE expression was detected in our HEK293 cell line at the mRNA level before transgene introduction.

Protein expression and purification for AlphaScreen binding studies. His-tagged human RAGE extracellular domain and deletion mutants containing the $\mathrm{V}$ domain (amino acids 1-121), V-C1 domains (amino acids 1-258), or C1-C2 domains (amino acids 122-342) were amplified by PCR and cloned into a His-tag-containing plasmid. For the C1-C2 deletion mutant, the RAGE leader sequence was added to the constructs by overlapping extension PCR. To generate recombinant RAGE deletion mutant proteins, expression vectors were transfected into Freestyle 293F cells (Invitrogen) and His-tagged proteins were subsequently purified from the cell culture supernatants using a HisTrap column (GE Healthcare) and a DuoFlow FPLC system (Bio-Rad Laboratories). Proteins were eluted from the column in highsalt buffer containing $500 \mathrm{mM}$ sodium chloride and $25 \mathrm{mM}$ imidazole, and dialyzed against PBS.

Protein expression and purification for structural analysis. Human RAGEV-C1 domain (residues 23-237) was expressed in bacteria and purified using metal-ion affinity, hydrophobic interaction, and size-exclusion chromatography. The V-C1 domain (Ala23 to Glu237) of human RAGE was cloned into a pET30a vector (EMD Biosciences) with a TEV cleavable N-terminal GB1 tag. Transformed BL21 (DE3) Codon Plus RIPL cells (Stratagene) were grown at $37^{\circ} \mathrm{C}$ until OD600 reached 1.2. Cells were then induced with $0.2 \mathrm{mM}$ IPTG at $18^{\circ} \mathrm{C}$ for $4 \mathrm{~h}$, harvested, and resuspended in a buffer containing 
$100 \mathrm{mM} \mathrm{NaCl}, 5 \mathrm{mM}$ imidazole, and $20 \mathrm{mM}$ Tris-HCl, $\mathrm{pH}$ 8.0, supplemented with DNase (Biomatik) and protease inhibitors (Roche). Cells were lysed by sonication, and soluble protein was purified from cleared cell lysate by HisPrep IMAC column (GE Healthcare). Nonspecific DNA contaminants were removed by adding ammonium sulfate powder to the IMAC elution fractions to a final concentration of $3 \mathrm{M}$. The protein pellet was dissolved in a buffer containing $100 \mathrm{mM} \mathrm{NaCl}$ and $20 \mathrm{mM}$ Tris-HCl, $\mathrm{pH}$ 8.0, before TEV protease cleavage of the expression tag. The RAGEV-C1 domain was further purified by a second IMAC column, followed by phenyl-Sepharose hydrophobic interaction chromatography and size exclusion chromatography.

Binding studies. Binding of biotinylated ODNs to purified, His-tagged, human RAGE domains was assayed in a buffer $(50 \mathrm{mM}$ Tris- $\mathrm{HCl} \mathrm{pH} 7.4$, $100 \mathrm{mM} \mathrm{NaCl}, 1 \%$ ultrapure BSA, $0.01 \%$ Tween 20) using an amplified luminescent proximity assay with streptavidin-conjugated donor beads and nickel chelate acceptor beads (AlphaScreen; Perkin Elmer; Schlee et al., 2009). For cell-binding studies, HeLa cells coexpressing RAGE-CFP and Rab4a-YFP or expressing only Rab4a-YFP were incubated with $1 \mu \mathrm{M}$ Alexa Fluor $647-$ labeled ODN 2336 at $37^{\circ} \mathrm{C}$ for $5 \mathrm{~min}$, washed with medium, and imaged by confocal microscopy. $293 \mathrm{~T}$ cells expressing tetracycline-inducible RAGEmCitrine were tetracycline-induced for $24 \mathrm{~h}$ or left untreated, and then incubated with $1 \mu \mathrm{M}$ Alexa Fluor 647-labeled ODN 2336 on ice for $30 \mathrm{~min}$. Cells were washed with PBS and analyzed on a BD LSR II instrument (Becton Dickinson) using FACSDiva (BD) and Flowjo software (Tree Star). For coimmunoprecipitation of TLR 9 and RAGE, U373 glioma epithelial cells virally transduced with the indicated proteins were incubated for $1 \mathrm{~h}$ with $1 \mu \mathrm{M}$ ODN 2006 or with culture medium only. Cells were lysed and incubated with protein A-coated Dynabeads (Invitrogen) and rabbit polyclonal antiGFP antibody (Invitrogen). Proteins captured on the beads were resolved by SDS-PAGE and TLR 9 and RAGE were detected by immunoblotting.

DNA uptake studies. HEK293 cells (Fig. 6) expressing tetracycline-inducible RAGE-mCitrine were induced with $1 \mu \mathrm{g} / \mathrm{ml}$ tetracycline overnight or left untreated, and then incubated with Alexa Fluor 647-labeled ODN 2006 , ODN 2336, or transferrin for $30 \mathrm{~min}$ as indicated and, after PBS washes, analyzed on a LSRII instrument (BD) using FACSDiva (BD) and FlowJo software (Tree Star). HeLa RAGE-CFP cells coexpressing either Rab5a-RFP or Rab9a-YFP were cultured on glass-bottom dishes (MatTek) pulsed with $500 \mathrm{nM}$ Alexa Fluor 647 -labeled ODN in medium for $5 \mathrm{~min}$ at $37^{\circ} \mathrm{C}$, washed with PBS, and then incubated in medium for the indicated time periods before imaging by confocal microscopy as detailed below. Channel line analyses were done using Volocity software (PerkinElmer). 293T cells (Fig. 7) were induced with $500 \mathrm{ng} / \mathrm{ml}$ doxycycline overnight or left untreated, and then incubated with Alexa Fluor 647 -labeled ODN 2006 or 2336 at $37^{\circ} \mathrm{C}$ for the indicated times. Excess oligonucleotides were removed by washing and cells were analyzed by flow cytometry as mentioned above. For imaging, 293 cells expressing tetracycline-inducible RAGE-mCitrine or RAGE-dCmCitrine (Fig. 7) were treated for $24 \mathrm{~h}$ with $10 \mathrm{ng} / \mathrm{ml}$ doxycycline, washed, and subsequently stimulated with $250 \mathrm{nM}$ ODN 2336. Images were acquired by confocal microscopy as detailed below.

Crystallization of the RAGE-DNA complex. DNA oligos were synthesized by IDT without a $5^{\prime}$-phosphate. dsDNA with different sequences and lengths were tested in co-crystallization with the RAGE V-C1 domain. The two 22mer dsDNA oligos used in the current crystal structures were derived from vaccinia virus genomic repeat sequences (annealed from $5^{\prime}$-CCATGACTGTAGGAAACTCTAG- $3^{\prime}$ and $5^{\prime}$-GCTAGAGTTTCCTACAGTCATG-3') and CpG sequences (annealed from 5'-CTGCAACGATGCTACGAACGTG-3' and $5^{\prime}$-CACGTTCGTAGCATCGTTGCAG-3'). Oligos were dissolved in a buffer containing $100 \mathrm{mM} \mathrm{KCl,} 5 \mathrm{mM}$ DTT, $20 \mathrm{mM}$ Hepes, pH 7.4. Complementary oligos were mixed at a 1:1 molar ratio, heated to $95^{\circ} \mathrm{C}$, and annealed by slow cooling to room temperature. Annealed dsDNAs were added to diluted protein solutions $(1 \mathrm{mg} / \mathrm{ml})$, and the protein-DNA complexes were concentrated with centrifugal concentrators (Millipore) to $10-20 \mathrm{mg} / \mathrm{ml}$ before setting up crystallization using the hanging drop vapor diffusion method. The RAGE V-C1-DNA complex was crystallized with a well solution containing $12 \%$ PEG6000, and $0.1 \mathrm{M}$ Tris- $\mathrm{HCl} \mathrm{pH}$ 7.4. A solution containing 12\% PEG6000, 10\% ethylene glycol, $10 \%$ glycol, and $0.1 \mathrm{M}$ Tris- $\mathrm{HCl}, \mathrm{pH} 7.4$, was used as a cryoprotectant to freeze crystals in liquid nitrogen before data collection.

$\mathrm{X}$-ray diffraction, structure determination, and refinement. $\mathrm{X}$-ray diffraction data were collected at GM/CA-CAT at the Advanced Photon Source (APS; Argonne). Data were processed with the HKL200 program suite (Otwinowski and Minor, 1997) and XDS (Kabsch, 2010). The RAGE V-C1-DNA structures were determined by molecular replacement with Phaser (McCoy et al., 2007) from the CCP4 program suite (Potterton et al., 2003). Previously reported RAGE structures (Koch et al., 2010; Park and Boyington, 2010), and ideal dsDNAs from Coot (Emsley and Cowtan, 2004) or make_na server (Lakshiminarayanan and Sasisekharan, 1970) were used as the initial search models. Structure building and refinement were performed with Coot and Phenix (Adams et al., 2010) and are summarized in Table 1. The final refined models show no gross structural changes for RAGE upon DNA binding. DNA base pair hydrogen bonding restraints were generated by the three-dimensional restraints server (Laurberg et al., 2008) and applied during refinement. TLS parameters were generated by the TLSMD server (Painter and Merritt, 2006) and Phenix (Adams et al., 2010) and applied throughout the refinement. Final structural models were validated by the Molprobity server (Chen et al., 2010) and RCSB ADIT validation server (Yang et al., 2004). Electrostatic charge surfaces were calculated with program Delphi (Honig and Nicholls, 1995) and displayed in Pymol (Delano Scientific LLC). The structures and $\mathrm{x}$-ray diffraction data were deposited at the RCSB Protein Data Bank with accession codes 3S58 and 3S59.

Fluorescence polarization assay. 5'-fluorescein (FAM) labeled 20mer DNA oligo ODN 787 (Table S1) was dissolved in 20 mM Tris-HCl, pH 8.0, and $100 \mathrm{mM} \mathrm{NaCl}$ and annealed with its reverse complement ODN 788. Purified RAGE wild-type or mutants were mixed with $3 \mathrm{nM}$ FAM-labeled dsDNA and diluted into assay buffers containing $20 \mathrm{mM}$ Hepes-Na, $\mathrm{pH} 7.4$, and $100 \mathrm{mM} \mathrm{NaCl}$. The mixtures were then aliquoted in triplets into black 96-well plates and fluorescence polarization was measured with a Paradigm spectrometer (Molecular Devices). Data were analyzed and plotted using GraphPad Prism software version 5.0 (GraphPad Software, Inc.). In addition to the "mutant 1" containing mutations at site 1 (K37A, K39A, K43A, and K107A; Fig. 3 A) and "mutant 2" at site 2 (R29A, Y118A, K123A, and R218A), we analyzed DNA binding by an irrelevant mutant ("mutant 0") containing mutations at three basic residues outside of the DNA-binding surface (K110A, R178A, and R179A).

Confocal microscopy. Live cells were imaged on glass-bottom culture dishes (MatTek) after overnight culture. Images shown represent a single $z$ plane though the approximate center of the cells of interest. Images were obtained with an SP2 AOBS laser scanning confocal microscope (Leica) using a $63 \times 1.4$ NA oil immersion objective (images in Figs. 1 and 6) or a SP5 SMD (Leica) using a $63 \times 1.2 \mathrm{NA}$ water immersion objective (images in Figs. 5 and 7). Sequential scanning was used to avoid cross excitation between fluorescence channels. Scale bars are approximate.

Förster resonance energy transfer (FRET) measurements. HEK293 cells coexpressing RAGE-CFP and RAGE-YFP were brought into suspension and incubated in PBS with the indicated CpG ODN on ice for $20 \mathrm{~min}$. After incubation at $37^{\circ} \mathrm{C}$ for $5 \mathrm{~min}$, the cells were washed with ice-cold PBS and kept on ice until flow cytometry FRET analysis was performed as previously described (Szentesi et al., 2004). RAGE-CFP or RAGE-YFP single transfectants were used as controls. Microscopy-based sensitized emission FRET was performed using a SP5 SMD confocal microscope. HEK293 cells were cultured on glass-bottom dishes and incubated with $10 \mu \mathrm{g} / \mathrm{ml}$ doxycycline for $24 \mathrm{~h}$ to express tetracycline-inducible RAGE-mCerulean and RAGE-mCitrine alone (as controls) or together. Cells were then treated with $0.25 \mu \mathrm{M}$ Alexa Fluor 647-labeled ODN 2006 or 2336 for $15-30 \mathrm{~min}$ at 
$37^{\circ} \mathrm{C}$ and imaged. FRET efficiency in areas of DNA-RAGE interaction was assessed by TCS software (Leica) and color coded as indicated, and representative cells were graphed using TCS software values and Prism (GraphPad Software, Inc.).

RAGE cross-linking. HEK RAGE-mCitrine cells in suspension $\left(3 \times 10^{5}\right.$ per sample) were incubated in PBS with or without bis(sulfosuccinimidyl) suberate (BS3; Thermo Fisher Scientific) for $30 \mathrm{~min}$ on ice. After pelleting the cells and removing the supernatant, cells were lysed in Laemmli buffer and samples were analyzed by SDS-PAGE and immunoblot with anti-GFP monoclonal antibody (Takara Bio Inc.).

Luciferase reporter assays. HEK293 cells stably expressing human TLRs 2 and 9, tetracycline-inducible human RAGE-mCerulean, and a firefly luciferase gene under the control of the NF- $\mathrm{KB}$-inducible ELAM promoter were incubated overnight with $10 \mu \mathrm{g} / \mathrm{ml}$ doxycycline to induce RAGE expression, or left uninduced. Cells were stimulated as indicated for $8-16 \mathrm{~h}$, and luciferase activity was assessed using SteadyGlo substrate (Promega) and an Envision multi-well plate reader (PerkinElmer). HEK293 cells stably expressing human TLR9 and tetracycline-inducible human RAGE-mCerulean were co-cultured with immortalized mouse C57BL6 macrophages alone or with silica (Min-U-Sil 15, Western Reserve Chemical) for $6 \mathrm{~h}$ before luciferase analysis or confocal microscopy.

Mice and in vivo studies. RAGE-deficient $\left(\right.$ ager $\left.^{-/-}\right)$mice were generated by Taconic Artemis Pharmaceuticals as previously described (Miller et al., 2012). Experiments were approved by the MedImmune, LLC internal Institutional Animal Care and Use Committee (IACUC), protocol MI-09-007. Mice were anesthetized with Isoflurane before intranasal inoculation of $5 \mu \mathrm{g}$ of CpG-B ODN 1826 in a total volume of $50 \mu \mathrm{l}$ of PBS. $24 \mathrm{~h}$ after DNA administration, BAL fluid (BALF) was collected by $3 \times 0.6 \mathrm{ml}$ washes with PBS/10 mM EDTA/20 mM Hepes, and lungs were harvested for histology. Lung tissue was inflated with $10 \%$ formalin before paraffin embedding, sectioning, and staining with hematoxylin and eosin. Cytokines in BALF were assessed by an ELISA-based MSD multiplex (MesoScale Diagnostics). IFN- $\alpha$ (PBL Interferon Source), and LIX (R\&D Systems) were measured by ELISA. Data shown are from one of two independent experiments with similar results.

Statistical analyses. Error bars in figures represent standard error of the mean for multiple samples. Significance of differences in uptake studies was assessed by one-tailed, unpaired $t$ test. Tests compared the uninduced and induced cells for each transfected construct, as well as each RAGE construct to control for the induced cells, as indicated in the figure. Significance of differences in in animal studies was evaluated using nonparametric Mann-Whitney $U$ tests with $\alpha$ defined as 0.05 . Tests compared the untreated and DNAtreated group of the same genotype, and the DNA-treated group of each genotype, as indicated in the figure. Prism software (GraphPad Software, Inc.) was used for all statistical analyses.

Online supplemental material. Table S1 shows oligonucleotide sequences and sources. Online supplemental material is available at http://www.jem .org/cgi/content/full/jem.20120201/DC1.

The authors would like to thank beam line scientists at GM/CA-CAT for their support, Patrick Smith for technical assistance, and Dr. Marlon Rebelatto for histopathology analysis.

T.S. Xiao is supported by the Division of Intramural Research, National Institute of Allergy and Infectious Diseases, National Institutes of Health $(\mathrm{NIH})$. E. Latz is supported in part by grants from the NIH and the Deutsche Forschungsgesellschaft (DFG, SFB704). E. Latz is a member of the ImmunoSensation Excellence cluster of the DFG and a member of the German Center for Infectious Diseases (DZIF).

The authors declare no financial conflicts of interest regarding this research.

Submitted: 26 January 2012

Accepted: 19 August 2013

\section{REFERENCES}

Adams, P.D., P.V. Afonine, G. Bunkóczi, V.B. Chen, I.W. Davis, N. Echols, J.J. Headd, L.W. Hung, G.J. Kapral, R.W. Grosse-Kunstleve, et al. 2010. PHENIX: a comprehensive Python-based system for macromolecular structure solution. Acta Crystallogr. D Biol. Crystallogr. 66:213-221. http://dx .doi.org/10.1107/S0907444909052925

Allmen, E.U., M. Koch, G. Fritz, and D.F. Legler. 2008.V domain of RAGE interacts with AGEs on prostate carcinoma cells. Prostate. 68:748-758. http://dx.doi.org/10.1002/pros.20736

Banerjee, S., A. Friggeri, G. Liu, and E. Abraham. 2010.The C-terminal acidic tail is responsible for the inhibitory effects of HMGB1 on efferocytosis. J. Leukoc. Biol. 88:973-979.http://dx.doi.org/10.1189/jlb.0510262

Barton, G.M., J.C. Kagan, and R. Medzhitov. 2006. Intracellular localization of Toll-like receptor 9 prevents recognition of self DNA but facilitates access to viral DNA. Nat. Immunol. 7:49-56. http://dx.doi.org/10 $.1038 /$ ni1280

Bierhaus, A., S. Schiekofer, M. Schwaninger, M. Andrassy, P.M. Humpert, J. Chen, M. Hong, T. Luther, T. Henle, I. Klöting, et al. 2001. Diabetesassociated sustained activation of the transcription factor nuclear factorkappaB. Diabetes. 50:2792-2808. http://dx.doi.org/10.2337/diabetes .50 .12 .2792

Blasius, A.L., C.N. Arnold, P. Georgel, S. Rutschmann, Y. Xia, P. Lin, X. Li, N.G. Smart, B. Beutler. 2010. Slc15a4, AP-3, and Hermansky-Pudlak syndrome proteins are required for Toll-like receptor signaling in plasmacytoid dendritic cells. Proc. Natl. Acad. Sci. USA 107:19973-19978.

Brett, J., A.M. Schmidt, S.D. Yan, Y.S. Zou, E. Weidman, D. Pinsky, R. Nowygrod, M. Neeper, C. Przysiecki, A. Shaw, et al. 1993. Survey of the distribution of a newly characterized receptor for advanced glycation end products in tissues. Am. J. Pathol. 143:1699-1712.

Buckley, S.T., and C. Ehrhardt. 2010. The receptor for advanced glycation end products (RAGE) and the lung. J. Biomed. Biotechnol. 2010:917108. http://dx.doi.org/10.1155/2010/917108

Chen, V.B., W.B. Arendall III, J.J. Headd, D.A. Keedy, R.M. Immormino, G.J. Kapral, L.W. Murray, J.S. Richardson, and D.C. Richardson. 2010. MolProbity: all-atom structure validation for macromolecular crystallography. Acta Crystallogr. D Biol. Crystallogr. 66:12-21. http://dx.doi.org/ 10.1107/S0907444909042073

Chuang, T.H., and R.J. Ulevitch. 2000. Cloning and characterization of a sub-family of human toll-like receptors: hTLR7, hTLR8 and hTLR9. Eur. Cytokine Netw. 11:372-378.

Crow,Y.J., and J.Rehwinkel.2009.Aicardi-Goutieres syndrome and related phenotypes: linking nucleic acid metabolism with autoimmunity. Hum. Mol. Genet. 18(R2):R130-R136.http://dx.doi.org/10.1093/hmg/ddp293

Dapić, V., V. Abdomerović, R. Marrington, J. Peberdy, A. Rodger, J.O. Trent, and P.J. Bates. 2003. Biophysical and biological properties of quadruplex oligodeoxyribonucleotides. Nucleic Acids Res. 31:20972107. http://dx.doi.org/10.1093/nar/gkg316

Dattilo, B.M., G. Fritz, E. Leclerc, C.W. Kooi, C.W. Heizmann, and W.J. Chazin. 2007. The extracellular region of the receptor for advanced glycation end products is composed of two independent structural units. Biochemistry. 46:6957-6970. http://dx.doi.org/10.1021/bi7003735

Demling, N., C. Ehrhardt, M. Kasper, M. Laue, L. Knels, and E.P. Rieber. 2006. Promotion of cell adherence and spreading: a novel function of RAGE, the highly selective differentiation marker of human alveolar epithelial type I cells. Cell Tissue Res. 323:475-488. http://dx.doi .org/10.1007/s00441-005-0069-0

Dumitriu, I.E., M.E. Bianchi, M. Bacci, A.A. Manfredi, and P. RovereQuerini. 2007. The secretion of HMGB1 is required for the migration of maturing dendritic cells. J. Leukoc. Biol. 81:84-91. http://dx.doi .org/10.1189/jlb.0306171

Emsley, P., and K. Cowtan. 2004. Coot: model-building tools for molecular graphics. Acta Crystallogr. D Biol. Crystallogr. 60:2126-2132. http:// dx.doi.org/10.1107/S0907444904019158

Evans, C.J., and R.J. Aguilera. 2003. DNase II: genes, enzymes and function. Gene. 322:1-15. http://dx.doi.org/10.1016/j.gene.2003.08.022

Ewald, S.E., B.L. Lee, L. Lau, K.E. Wickliffe, G.P. Shi, H.A. Chapman, and G.M. Barton. 2008. The ectodomain of Toll-like receptor 9 is cleaved to generate a functional receptor. Nature. 456:658-662. http://dx.doi .org/10.1038/nature07405 
Ewald, S.E., A. Engel, J. Lee, M. Wang, M. Bogyo, and G.M. Barton. 2011 Nucleic acid recognition by Toll-like receptors is coupled to stepwise processing by cathepsins and asparagine endopeptidase. J. Exp. Med. 208:643-651. http://dx.doi.org/10.1084/jem.20100682

Gregorio,J., S. Meller, C. Conrad,A. Di Nardo, B. Homey,A. Lauerma, N.Arai, R.L. Gallo, J. Digiovanni, and M. Gilliet. 2010. Plasmacytoid dendritic cells sense skin injury and promote wound healing through type I interferons. J. Exp. Med. 207:2921-2930. http://dx.doi.org/10.1084/jem.20101102

Haas, T., J. Metzger, F. Schmitz, A. Heit, T. Müller, E. Latz, and H. Wagner. 2008. The DNA sugar backbone 2 ' deoxyribose determines toll-like receptor 9 activation. Immunity. 28:315-323. http://dx.doi.org/10.1016/j .immuni.2008.01.013

Hartmann, G., R.D. Weeratna, Z.K. Ballas, P. Payette, S. Blackwell, I. Suparto, W.L. Rasmussen, M. Waldschmidt, D. Sajuthi, R.H. Purcell, et al. 2000. Delineation of a $\mathrm{CpG}$ phosphorothioate oligodeoxynucleotide for activating primate immune responses in vitro and in vivo. J. Immunol. 164:1617-1624

Hemmi, H., O. Takeuchi, T. Kawai, T. Kaisho, S. Sato, H. Sanjo, M. Matsumoto, K. Hoshino, H. Wagner, K. Takeda, and S. Akira. 2000. A Toll-like receptor recognizes bacterial DNA. Nature. 408:740-745. http://dx.doi .org/10.1038/35047123

Hofmann, M.A., S. Drury, C. Fu, W. Qu, A. Taguchi, Y. Lu, C. Avila, N Kambham, A. Bierhaus, P. Nawroth, et al. 1999. RAGE mediates a novel proinflammatory axis: a central cell surface receptor for S100/ calgranulin polypeptides. Cell. 97:889-901. http://dx.doi.org/10.1016/ S0092-8674(00)80801-6

Honda, K., Y. Ohba, H. Yanai, H. Negishi, T. Mizutani, A. Takaoka, C. Taya, and T. Taniguchi. 2005. Spatiotemporal regulation of MyD88IRF-7 signalling for robust type-I interferon induction. Nature. 434: 1035-1040. http://dx.doi.org/10.1038/nature03547

Honig, B., and A. Nicholls. 1995. Classical electrostatics in biology and chemistry. Science. 268:1144-1149. http://dx.doi.org/10.1126/science.7761829

Hornung, V., and E. Latz. 2010. Intracellular DNA recognition. Nat. Rev. Immunol. 10:123-130. http://dx.doi.org/10.1038/nri2690

Hornung, V., F. Bauernfeind, A. Halle, E.O. Samstad, H. Kono, K.L. Rock, K.A. Fitzgerald, and E. Latz. 2008. Silica crystals and aluminum salts activate the NALP3 inflammasome through phagosomal destabilization. Nat. Immunol. 9:847-856. http://dx.doi.org/10.1038/ni.1631

Horton, C.G., Z.J. Pan, and A.D. Farris. 2010. Targeting Toll-like receptors for treatment of SLE. Mediators Inflamm. 2010:2010.

Hudson, B.I., A.Z. Kalea, M. Del Mar Arriero, E. Harja, E. Boulanger, V. D'Agati, and A.M. Schmidt. 2008. Interaction of the RAGE cytoplasmic domain with diaphanous-1 is required for ligand-stimulated cellular migration through activation of Rac1 and Cdc42. J. Biol. Chem. 283:34457-34468. http://dx.doi.org/10.1074/jbc.M801465200

Huttunen, H.J., C. Fages, and H. Rauvala. 1999. Receptor for advanced glycation end products (RAGE)-mediated neurite outgrowth and activation of NF-kappaB require the cytoplasmic domain of the receptor but different downstream signaling pathways. J. Biol. Chem. 274:1991919924.http://dx.doi.org/10.1074/jbc.274.28.19919

Kabsch,W. 2010. Xds. Acta Crystallogr. D Biol. Crystallogr. 66:125-132. http:// dx.doi.org/10.1107/S0907444909047337

Kalea, A.Z., N. Reiniger, H.Yang, M. Arriero, A.M. Schmidt, and B.I. Hudson. 2009. Alternative splicing of the murine receptor for advanced glycation end-products (RAGE) gene. FASEB J. 23:1766-1774. http://dx.doi .org/10.1096/fj.08-117739

Kawane, K., H. Tanaka, Y. Kitahara, S. Shimaoka, and S. Nagata. 2010. Cytokine-dependent but acquired immunity-independent arthritis caused by DNA escaped from degradation. Proc. Natl. Acad. Sci. USA. 107:19432-19437. http://dx.doi.org/10.1073/pnas.1010603107

Koch, M., S. Chitayat, B.M. Dattilo, A. Schiefner, J. Diez, W.J. Chazin, and G. Fritz. 2010. Structural basis for ligand recognition and activation of RAGE. Structure. 18:1342-1352. http://dx.doi.org/10.1016/j.str.2010.05.017

Krieg, A.M. 2007. TLR9 and DNA 'feel' RAGE. Nat. Immunol. 8:475477.http://dx.doi.org/10.1038/ni0507-475

Lakshiminarayanan,A.V., andV. Sasisekharan. 1970. Stereochemistry of nucleic acids and polynucleotides. II. Allowed conformations of the monomer unit for different ribose puckerings. Biochim. Biophys. Acta. 204:49-59. http://dx.doi.org/10.1016/0005-2787(70)90489-2
Lander, H.M., J.M. Tauras, J.S. Ogiste, O. Hori, R.A. Moss, and A.M. Schmidt. 1997. Activation of the receptor for advanced glycation end products triggers a p21(ras)-dependent mitogen-activated protein kinase pathway regulated by oxidant stress. J. Biol. Chem. 272:17810-17814. http:// dx.doi.org/10.1074/jbc.272.28.17810

Laurberg, M., H. Asahara, A. Korostelev, J. Zhu, S. Trakhanov, and H.F. Noller. 2008. Structural basis for translation termination on the $70 \mathrm{~S}$ ribosome. Nature. 454:852-857.http://dx.doi.org/10.1038/nature07115

Li, J., and A.M. Schmidt. 1997. Characterization and functional analysis of the promoter of RAGE, the receptor for advanced glycation end products. J. Biol. Chem. 272:16498-16506. http://dx.doi.org/10.1074/jbc.272.26.16498

McCoy, A.J., R.W. Grosse-Kunstleve, P.D. Adams, M.D. Winn, L.C. Storoni, and R.J. Read. 2007. Phaser crystallographic software. J. Appl. Cryst. 40:658-674. http://dx.doi.org/10.1107/S0021889807021206

Miller, A.L., G.P. Sims,Y.A. Brewah, M.C. Rebelatto, J. Kearley, E. Benjamin, A.E. Keller, P. Brohawn, R. Herbst, A.J. Coyle, et al. 2012. Opposing roles of membrane and soluble forms of the receptor for advanced glycation end products in primary respiratory syncytial virus infection. J. Infect. Dis. 205:1311-1320. http://dx.doi.org/10.1093/infdis/jir826

Moser, B., D.D. Desai, M.P. Downie, Y. Chen, S.F. Yan, K. Herold, A.M Schmidt, and R. Clynes. 2007. Receptor for advanced glycation end products expression on $\mathrm{T}$ cells contributes to antigen-specific cellular expansion in vivo. J. Immunol. 179:8051-8058.

Napirei, M., H. Karsunky, B. Zevnik, H. Stephan, H.G. Mannherz, and T. Möröy. 2000. Features of systemic lupus erythematosus in Dnase1deficient mice. Nat. Genet. 25:177-181. http://dx.doi.org/10.1038/ 76032

Ostendorp, T., E. Leclerc, A. Galichet, M. Koch, N. Demling, B. Weigle, C.W. Heizmann, P.M. Kroneck, and G. Fritz. 2007. Structural and functional insights into RAGE activation by multimeric S100B. EMBO J. 26:3868-3878. http://dx.doi.org/10.1038/sj.emboj.7601805

Otwinowski, Z., and W. Minor. 1997. Processing of X-ray diffraction data collected in oscillation mode. Methods Enzymol. 276:307-326. http:// dx.doi.org/10.1016/S0076-6879(97)76066-X

Painter, J., and E.A. Merritt. 2006. Optimal description of a protein structure in terms of multiple groups undergoing TLS motion. Acta Crystallogr. D Biol. Crystallogr. 62:439-450. http://dx.doi.org/10.1107/ S0907444906005270

Park, H., F.G. Adsit, and J.C. Boyington. 2010. The 1.5 A crystal structure of human receptor for advanced glycation endproducts (RAGE) ectodomains reveals unique features determining ligand binding. J. Biol. Chem. 285:40762-40770.http://dx.doi.org/10.1074/jbc.M110 .169276

Park, B., M.M. Brinkmann, E. Spooner, C.C. Lee, Y.M. Kim, and H.L Ploegh. 2008. Proteolytic cleavage in an endolysosomal compartment is required for activation of Toll-like receptor 9. Nat. Immunol. 9:14071414.http://dx.doi.org/10.1038/ni.1669

Potterton, E., P. Briggs, M.Turkenburg, and E. Dodson. 2003. A graphical user interface to the CCP4 program suite. Acta Crystallogr. D Biol. Crystallogr. 59:1131-1137. http://dx.doi.org/10.1107/S0907444903008126

Ramasamy, R., S.F.Yan, and A.M. Schmidt. 2009. RAGE: therapeutic target and biomarker of the inflammatory response-the evidence mounts. J. Lenkoc. Biol. 86:505-512. http://dx.doi.org/10.1189/jlb.0409230

Ranjan, P., J.B. Bowzard, J.W. Schwerzmann, V. Jeisy-Scott, T. Fujita, and S. Sambhara. 2009. Cytoplasmic nucleic acid sensors in antiviral immunity. Trends Mol. Med. 15:359-368. http://dx.doi.org/10.1016/j .molmed.2009.06.003

Ruan, B.H., X. Li, A.R. Winkler, K.M. Cunningham, J. Kuai, R.M Greco, K.H. Nocka, L.J. Fitz, J.F. Wright, D.D. Pittman, et al. 2010 Complement C3a, CpG oligos, and DNA/C3a complex stimulate IFN- $\alpha$ production in a receptor for advanced glycation end productdependent manner. J. Immunol. 185:4213-4222. http://dx.doi.org/10 $.4049 /$ jimmunol.1000863

Sárkány, Z., T.P. Ikonen, F. Ferreira-da-Silva, M.J. Saraiva, D. Svergun, and A.M. Damas. 2011. Solution structure of the soluble receptor for advanced glycation end products (sRAGE). J. Biol. Chem. 286:3752537534. http://dx.doi.org/10.1074/jbc.M111.223438

Sasai, M., M.M. Linehan, and A. Iwasaki. 2010. Bifurcation of Toll-like receptor 9 signaling by adaptor protein 3. Science. 329:1530-1534. 
Schlee, M., A. Roth, V. Hornung, C.A. Hagmann, V. Wimmenauer, W. Barchet, C. Coch, M. Janke, A. Mihailovic, G. Wardle, et al. 2009 Recognition of 5' triphosphate by RIG-I helicase requires short blunt double-stranded RNA as contained in panhandle of negative-strand virus. Immunity. 31:25-34. http://dx.doi.org/10.1016/j.immuni.2009.05.008

Sims, G.P., D.C. Rowe, S.T. Rietdijk, R. Herbst, and A.J. Coyle. 2010. HMGB1 and RAGE in inflammation and cancer. Annu. Rev. Immunol. 28 367-388. http://dx.doi.org/10.1146/annurev.immunol.021908.132603

Srikrishna, G., J. Nayak, B. Weigle, A. Temme, D. Foell, L. Hazelwood, A. Olsson, N.Volkmann, D. Hanein, and H.H. Freeze. 2010. Carboxylated $\mathrm{N}$-glycans on RAGE promote S100A12 binding and signaling. J. Cell. Biochem. 110:645-659. http://dx.doi.org/10.1002/jcb.22575

Szentesi, G., G. Horváth, I. Bori, G. Vámosi, J. Szöllosi, R. Gáspár, S. Damjanovich, A. Jenei, and L. Mátyus. 2004. Computer program for determining fluorescence resonance energy transfer efficiency from flow cytometric data on a cell-by-cell basis. Comput. Methods Programs Biomed. 75:201-211. http://dx.doi.org/10.1016/j.cmpb.2004.02.004

Takeda, K., T. Kaisho, and S. Akira. 2003. Toll-like receptors. Annu. Rev Immunol. 21:335-376. http://dx.doi.org/10.1146/annurev.immunol.21 .120601 .141126

Tian, J., A.M. Avalos, S.Y. Mao, B. Chen, K. Senthil, H. Wu, P. Parroche, S. Drabic, D. Golenbock, C. Sirois, et al. 2007. Toll-like receptor 9-dependent activation by DNA-containing immune complexes is mediated by HMGB1 and RAGE. Nat. Immunol. 8:487-496. http://dx.doi .org/10.1038/ni1457

Vollmer, J., R. Weeratna, P. Payette, M. Jurk, C. Schetter, M. Laucht, T. Wader, S. Tluk, M. Liu, H.L. Davis, and A.M. Krieg. 2004. Characterization of three $\mathrm{CpG}$ oligodeoxynucleotide classes with distinct immunostimulatory activities. Eur. J. Immunol. 34:251-262. http://dx.doi.org/ 10.1002/eji.200324032

Xu, D., J.H. Young, J.M. Krahn, D. Song, K.D. Corbett, W.J. Chazin, L.C. Pedersen, and J.D. Esko. 2013. Stable RAGE-Heparan Sulfate Complexes Are Essential for Signal Transduction. ACS Chem. Biol.

Yan, S.D., A.M. Schmidt, G.M. Anderson, J. Zhang, J. Brett,Y.S. Zou, D. Pinsky, and D. Stern. 1994. Enhanced cellular oxidant stress by the interaction of advanced glycation end products with their receptors/binding proteins. J. Biol. Chem. 269:9889-9897.

Yan, S.F., S.D. Yan, R. Ramasamy, and A.M. Schmidt. 2009. Tempering the wrath of RAGE: an emerging therapeutic strategy against diabetic complications, neurodegeneration, and inflammation. Ann. Med. 41:408422.http://dx.doi.org/10.1080/07853890902806576

Yanai, H., T. Ban, Z. Wang, M.K. Choi, T. Kawamura, H. Negishi, M. Nakasato, Y. Lu, S. Hangai, R. Koshiba, et al. 2009. HMGB proteins function as universal sentinels for nucleic-acid-mediated innate immune responses. Nature. 462:99-103. http://dx.doi.org/10.1038/nature08512

Yang, H., V. Guranovic, S. Dutta, Z. Feng, H.M. Berman, andJ.D. Westbrook. 2004. Automated and accurate deposition of structures solved by X-ray diffraction to the Protein Data Bank. Acta Crystallogr. D Biol. Crystallogr. 60:1833-1839. http://dx.doi.org/10.1107/S0907444904019419

Zong, H., A. Madden, M. Ward, M.H. Mooney, C.T. Elliott, and A.W. Stitt. 2010. Homodimerization is essential for the receptor for advanced glycation end products (RAGE)-mediated signal transduction. J. Biol. Chem. 285:23137-23146.http://dx.doi.org/10.1074/jbc.M110 .133827 